$11-2015$

\title{
What Happens Before? A Field Experiment Exploring How Pay and Representation Differentially Shape Bias on the Pathway into Organizations
}

\author{
Katherine L. Milkman \\ University of Pennsylvania \\ Modupe Akinola \\ Dolly Chugh
}

Follow this and additional works at: https://repository.upenn.edu/fnce_papers

Part of the Finance and Financial Management Commons, and the Social and Behavioral Sciences Commons

\section{Recommended Citation}

Milkman, K. L., Akinola, M., \& Chugh, D. (2015). What Happens Before? A Field Experiment Exploring How Pay and Representation Differentially Shape Bias on the Pathway into Organizations. Journal of Applied Psychology, 100 (6), 1678-1712. http://dx.doi.org/10.1037\%2Fapl0000022 


\title{
What Happens Before? A Field Experiment Exploring How Pay and Representation Differentially Shape Bias on the Pathway into Organizations
}

\author{
Abstract \\ Little is known about how discrimination manifests before individuals formally apply to organizations or \\ how it varies within and between organizations. We address this knowledge gap through an audit study in \\ academia of over 6,500 professors at top U.S. universities drawn from 89 disciplines and 259 institutions. \\ In our experiment, professors were contacted by fictional prospective students seeking to discuss \\ research opportunities prior to applying to a doctoral program. Names of students were randomly \\ assigned to signal gender and race (White, Black, Hispanic, Indian, Chinese), but messages were \\ otherwise identical. We hypothesized that discrimination would appear at the informal "pathway" \\ preceding entry to academia and would vary by discipline and university as a function of faculty \\ representation and pay. We found that when considering requests from prospective students seeking \\ mentoring in the future, faculty were significantly more responsive to White males than to all other \\ categories of students, collectively, particularly in higher-paying disciplines and private institutions. \\ Counterintuitively, the representation of women and minorities and discrimination were uncorrelated, a \\ finding that suggests greater representation cannot be assumed to reduce discrimination. This research \\ highlights the importance of studying decisions made before formal entry points into organizations and \\ reveals that discrimination is not evenly distributed within and between organizations.

\section{Disciplines} \\ Finance and Financial Management | Social and Behavioral Sciences
}


What Happens Before? A Field Experiment Exploring How Pay and Representation Differentially Shape Bias on the Pathway into Organizations

\author{
Katherine L. Milkman \\ The University of Pennsylvania
}

Modupe Akinola

Columbia University

Dolly Chugh

New York University

ACKNOWLEDGEMENTS: We thank Professors Max Bazerman, Eric Bradlow, Joel Brockner, Gerard Cachon, Eugene Caruso, Emilio Castilla, Roberto Fernandez, Adam Galinsky, Jack Hershey, Raymond Horton, Stephan Meier, Ruth Milkman, Amanda Pallais, Lakshmi Ramarajan, and Brian Rubineau for insightful feedback on this paper. We also thank Fabiano Prestes, Stan Liu, Katie Shonk, and our research assistants for extensive support. Finally, we thank the Russell Sage Foundation and the Wharton Dean's Research Fund for funding this work. 


\begin{abstract}
Little is known about how bias against women and minorities varies within and between organizations or how it manifests before individuals formally apply to organizations. We address this knowledge gap through an audit study in academia of over 6,500 professors at top U.S. universities drawn from 89 disciplines and 259 institutions. We hypothesized that discrimination would appear at the informal "pathway" preceding entry to academia and would vary by discipline and university as a function of faculty representation and pay. In our experiment, professors were contacted by fictional prospective students seeking to discuss research opportunities prior to applying to a doctoral program. Names of students were randomly assigned to signal gender and race (Caucasian, Black, Hispanic, Indian, Chinese), but messages were otherwise identical. We found that faculty ignored requests from women and minorities at a higher rate than requests from White males, particularly in higher-paying disciplines and private institutions. Counterintuitively, the representation of women and minorities and bias were uncorrelated, suggesting that greater representation cannot be assumed to reduce bias. This research highlights the importance of studying what happens before formal entry points into organizations and reveals that discrimination is not evenly distributed within and between organizations.
\end{abstract}

Keywords: Diversity, Discrimination, Pay, Academia 
It is well known that women and minorities are underrepresented in organizations, particularly at the highest echelons (Smith, 2002; Bertrand, Goldin and Katz, 2010; McGinn and Milkman, 2013), despite widespread efforts to promote diversity (Kalev, Dobbin, and Kelly, 2006; Dobbin, Kim, and Kalev, 2011). In academia, the majority (60\%) of full professors at U.S. postsecondary institutions are White males, while $28 \%$ are female, $7 \%$ are Asian, $3 \%$ are Black, and 3\% are Hispanic (U.S. Department of Education, 2010), and underrepresentation for many groups begins in early as early as doctoral programs (U.S. Department of Education, 2014). Scholars have produced considerable evidence suggesting that bias is a possible contributor to this pattern, affecting hiring, pay, promotion, tenure, and funding outcomes (see Cole, 1979; Long and Fox, 1995; Valian, 1999). However, two important gaps limit our ability to understand and address this bias. First, our knowledge is based on extensive documentation of how women and minorities are differentially treated relative to Caucasian males once they have entered the Academy and other non-academic institutions; we know little about bias that may occur in the informal processes leading up to the attempt to enter. Specifically, racial and gender bias that occurs prior to applying to a $\mathrm{PhD}$ program may contribute to the underrepresentation of minorities and women in academia. Second, while most metrics studied in academia show differences in treatment by gender and race, few studies allow for causal inference or have been broad enough to explore where bias is most extreme. As a result, greater knowledge of where bias may play a causal role in explaining observed racial and gender differences in academic and non-academic contexts is needed.

Our paper focuses on "what happens before" someone chooses to apply to an organization. We investigate whether and where women and minorities considering graduate school enrollment may experience disproportionately less support in the early, informal 
processes leading up to the decision to apply. We propose that differential treatment at this stage is a possible factor in the underrepresentation of women and minorities in the ranks of both doctoral students and professors, and that this bias may similarly impede careers in other organizations.

We directly examine faculty bias toward women and minorities using methods that allow for causal inference. Specifically, we present new analyses of a field experiment in which 6,548 tenure-track professors at 259 top U.S. universities in 109 different PhD-granting disciplines were contacted by fictional prospective doctoral students seeking a meeting to discuss research opportunities. The names of the "students" were randomly assigned to signal gender and race (Caucasian, Black, Hispanic, Indian, Chinese), but their messages were otherwise identical. Our outcome of interest is whether and which faculty responded to these inquiries. We provide direct, quantitative evidence of whether, where, and when academia fails to offer women and minorities the same encouragement, guidance, and research opportunities offered to Caucasian men prior to formal application to a doctoral program.

Our findings contribute to the scholarship on bias in organizations in several important ways. First, we bring new attention to what happens before the formal processes required to gain admission into an organization begin. We provide evidence that many prospective minority and female students may be dissuaded from entering "pathways" leading to the Academy before ever reaching the "gateway" officially providing or denying them entry (Chugh and Brief, 2008). In doing so, this study contributes to the literature on discrimination in organizations by highlighting that in addition to bias at gateways, bias at pathways can hinder the advancement of women and minorities. 
Second, our use of a field experiment methodology allows us to make causal inferences about bias and measure its magnitude and extent. Previous research about bias in academia and non-academic institutions has relied primarily on correlational and qualitative methods which, respectively, leave open alternative explanations for patterns detected and the magnitude of bias. We therefore address these constraints through an audit study offering high experimental control.

Third, studies of discrimination in which individuals realize they are being observed (e.g., qualitative and laboratory studies) may suffer from social desirability bias and thus fail to measure implicit, unconscious, or unintentional bias, which many have argued could be a more pernicious problem than explicit, conscious, or unintentional bias in the modern era (Greenwald and Banaji, 1995; Valian, 1999; Bertrand, Chugh, and Mullainathan, 2005; Quillian, 2006; Pager and Shepherd, 2008; Ridgeway, 2009; Sue, 2010). To the extent that unconscious bias may be contributing to discrimination, unobtrusive methods for studying discrimination are critical. Audit experiments - those in which pairs of matched testers who differ only on race, gender, or some other dimension of interest attempt to obtain a desired outcome using identical techniques while treatment differences are measured - are therefore of particularly high value (Quillian, 2006; Pager, 2007). By exposing faculty in various disciplines to students who differ only in race and gender, we can examine the extent to which race and gender consciously or unconsciously influence decision making.

Finally, and arguably most importantly, we examine where bias is most pronounced in and across organizations. The breadth of our experiment gives us the ability to address the critical question of whether bias is evenly distributed or instead more pronounced under certain conditions. Specifically, we examine how a given minority group's representation relates to the degree of bias that minority group experiences, offering new insights about the influence of 
"homophily," or the tendency to prefer associating with those are similar to us (e.g., see McPherson, Smith-Lovin and Cook, 2001), on discrimination. Additionally, we examine how faculty salary relates to bias, linking recent research on the influence of money on ethicality and generosity (Piff et al., 2010; Caruso et al., 2012; Piff et al. 2012) to the important issue of discrimination.

We begin by distinguishing between the formal "gateway" points of entry into organizations and more informal "pathway" processes that can precede the point of entry. We next discuss the factors that make academia an especially important context for the exploration of discrimination using unobtrusive measures. We then turn to a review of the literature offering evidence that discrimination remains a problem in the Academy and beyond, and develop a set of hypotheses about where we expect to observe bias in the Academy. Finally, we present the methods and results from our field experiment and conclude with a discussion that highlights the contribution of this work to furthering our understanding of the barriers to increasing representation of women and minorities in academia and other organizations in which they are underrepresented.

\section{DISCRIMINATION AT GATEWAYS VERSUS PATHWAYS IN ACADEMIA AND BEYOND}

Gateways are the entry points into valued organizations, communities, or institutions, while pathways describe the more fluid processes that influence one's ability to access an entry point and to be successful after entry (Chugh and Brief, 2008). Past research examining race and gender bias in organizations and in the Academy, in particular, has focused largely on the obstacles that women and minorities face at formal gateways to those institutions (e.g., in admissions decisions and hiring decisions; see Kolpin and Singell, 1996; Attiyeh and Attiyeh, 
1997; Steinpreis, Anders and Ritzke, 1999; Bertrand and Mullainathan, 2004; Pager, Western and Bonikowski, 2009; Moss-Racusin et al., 2012) and on the performance of these groups once they have entered (e.g., grades, promotions, pay, job satisfaction, turnover; see Simons, Andrews, and Rhee, 1995; Tolbert, et al., 1995; Toutkoushian, 1998; Castilla and Benard, 2010; Carr et al., 2012; Sonnert and Fox, 2012; McGinn and Milkman, 2013). However, before an individual can be granted or denied admission to an organization, or begin to compete for accolades, she must decide whether to apply, and self-assessments shaped by others' treatment of her can influence such decisions (Correll, 2001; Correll, 2004). It is therefore critical to examine race and gender bias that may occur along pathways leading to gateways, which govern whether an individual elects to apply to an institution.

Positive outcomes along pathways and at gateways can determine success in academia and in other organizations. For example, along the pathway to college, students must perceive opportunity in higher education (Lawrence and Tolbert, 1997), receive encouragement from teachers, friends, and parents to consider higher education, and complete the necessary prerequisites, such as standardized testing (Correll, 2001; Correll, 2004; Hoxby and Avery, 2012). We propose that an under-studied force may contribute to the underrepresentation of women and minorities in doctoral programs: namely, experiences along pathways to the Academy may deter them from entering the pool of applicants for doctoral programs. Ironically, these informal obstacles may unintentionally prevent an individual from ever reaching the gateway at which formal structures may be designed to encourage entry.

In this paper, we study how women and minorities are treated along the pathway to graduate school. Specifically, our field experiment focuses on whether and how faculty respond to inquiries from prospective doctoral students seeking encouragement, guidance, and research 
opportunities. Notably, the decision about whether to pursue a doctorate occurs at a critical career stage when many potential academics leave the pipeline (Seymour and Hewitt, 1997; U.S. Department of Education, 2009). If women and minorities are ignored at a higher rate than White males by prospective mentors when considering doctoral study, they may be more likely to be: (a) discouraged from applying for a doctorate, (b) disadvantaged in navigating the admissions process, having received less guidance on components of their application, (c) disqualified from serious consideration due to a lack of the very research experience they attempted to acquire, and (d) disconnected from the informal networks that undergird pathway processes both inside and outside academia. Replying (versus not replying) to an email from a student seeking research experience and considering a doctorate, the outcome variable of interest in our study, is the most visible signal that a faculty member has not entirely dismissed or overlooked the prospective student's interest. ${ }^{1}$

Our focus on pathways, particularly those preceding gateways, aligns well with the theory of cumulative disadvantage (Merton, 1973; Clark and Corcoron, 1986; DiPrete and Eirich, 2006), which presumes underrepresentation to be the result of many small differences in how members of minority groups are treated early in their careers, or a function of one small difference at an early stage that "accumulate[d] to [create] large between-group differences" (Ginther et al., 2011, p. 1019). Such mechanisms of cumulative (dis)advantage are frequently invoked as explanations for inequality (Merton, 1973; Clark and Corcoron, 1986; DiPrete and Eirich, 2006); yet, to our knowledge, previous empirical research has not examined the possibility that discouragement from even applying for opportunities may contribute to underrepresentation. For this reason, we examine the treatment of women and minorities at the

\footnotetext{
${ }^{1}$ We conducted a small survey study to validate the role of such pathway communications in graduate school admissions and success. Details are available upon request.
} 
point when prospective students contemplate an application to graduate school and seek guidance and encouragement from potential doctoral mentors.

\section{THE VALUE OF ACADEMIA AS AN ORGANIZATIONAL CONTEXT}

Academia is an ideal setting for an experiment examining discrimination in organizations for several reasons. First, academia serves as an entry point for nearly all professions. In addition, it is possible that the same faculty who discriminate against prospective $\mathrm{PhD}$ students may exhibit similar biases against students seeking to enter the non-academic workforce. Further, increasing female and minority representation among faculty in academia (which first requires increasing representation among those receiving doctorates) is associated with higher educational attainment for female and minority students, respectively (Trower and Chait, 2002; Sonnert, Fox and Adkins, 2007). Thus, bias against prospective doctoral students has important implications both for the Academy and for most non-academic organizations.

Second, academia offers a pragmatically unique context for a field experiment due to the ease of building a database describing its workforce. To our knowledge, few (if any) other professions are as richly described by publicly available records as academia; information about virtually all U.S. faculty members is easily retrievable online. This transparency allowed us to build our audit study's participant sample from the full universe of tenure-track faculty at the U.S. universities of interest and to obtain data on each faculty member's race, gender, disciplinary affiliation, institutional affiliation, and status (e.g., full professor, associate professor, or assistant professor). Additionally, reliable surveys exist that describe the average demographic makeup of academics by discipline and type of institution and their salary levels, furthering our ability to conduct interesting analyses (NSOFP, 2004; U.S. News and World 
Report, 2010). This is one of the many reasons that academia has been richly studied by other organizational scholars (e.g., Tolbert et al., 1995; Khurana, 2007).

Finally, the heterogeneity of academics along a number of interesting and observable dimensions makes academia an ideal setting for exploring the characteristics of an organization that exacerbate (or reduce) race and gender bias. For one, professors are heterogeneous in their areas of study (e.g., sociology, chemistry, nursing), and each academic discipline differs measurably in its student and faculty race and gender composition as well as its average salary. Furthermore, academic institutions vary in meaningful ways, including in the diversity of their student bodies and their perceived quality/rigor. At the same time, all tenure-track academics receive the same basic training (a doctoral degree) and conduct the same basic job functions (teaching students and conducting research). Thus, while holding education and job function constant, we are able to explore how organizational characteristics of theoretical interest relate to levels of race and gender bias.

\section{EVIDENCE OF DISCRIMINATION IN ACADEMIA AND BEYOND}

The prominent labor economist James Heckman has claimed that bias has been eliminated from the labor market (Heckman, 1998), and others have argued that discrimination is no longer a significant problem in the Academy, making affirmative-action programs unnecessary (Ceci and Williams, 2011; Stockdill and Danico, 2012). Such claims ignore substantial evidence suggesting that discrimination does indeed persist in today's labor market (e.g., see Neckerman and Kirschenman, 1991; Altonji and Blank, 1999; Bertrand and Mullainathan, 2004; Pager and Quillian, 2005; Massey, 2007; Pager, Western and Bonikowski, 2009), including in academia. These claims of equality and fairness highlight the importance of 
documenting exactly where (if anywhere) bias impedes females and minorities seeking entrance to the Academy and other organizations using unassailable methods.

Most past research exploring bias in academia has used an approach called "sophisticated residualism" (Cole, 1979: 29) to measure discrimination by looking at differences in outcomes by sex and race after controlling for relevant independent variables such as productivity (see Long and Fox, 1995 for a review). Such studies have revealed persistently worse treatment of both women and minorities relative to White males in pay (Barbezat, 1991; Ransom and Megdal, 1993; Ginther, 2006; Toutkoushian, 1998), promotions (Cole, 1979; Long, Allison, and McGuinness., 1993; Perna, 2001; Ginther, 2006), job prospects (Sonnert, 1990; Kolpin and Singell, 1996; Nakhaie, 2007), and funding opportunities (Ginther et al., 2011). However, these correlational studies are subject to the criticism that they omitted one or more potentially important but unobservable control variables (e.g., see Erickson, 2011).

Qualitative studies provide further evidence that bias continues to plague the Academy by showing that prejudice remains rampant at U.S. institutions of higher learning, creating an unpleasant environment for minority and female students and faculty (Clark and Corcoran, 1986; Anderson et al., 1993; Feagin and Sikes, 1995; Turner, Myers, and Creswell, 1999; Johnsrud and Sadao, 1998; Carr et al., 2000; Gersick, Dutton, and Bartunek, 2000). However, because participants in qualitative studies know their responses are being recorded and analyzed, they may be influenced by a social-desirability bias (Greenwald and Banaji, 1995), and such studies cannot necessarily measure unconscious bias (Greenwald and Banaji, 1995; Valian, 1999; Bertrand, Chugh, and Mullainathan, 2005; Quillian, 2006; Pager and Shepherd, 2008; Ridgeway, 2009; Sue, 2010) or provide insight into the magnitude of bias. 
Two experiments conducted in academia in which professors evaluated hypothetical job applicants provide some causal evidence of discrimination against women (Steinpreis, Andres, and Ritzke, 1999; Moss-Racusin et al., 2012). These studies, however, leave open questions about the persistence of gender bias in fields other than psychology, biology, physics, and chemistry, and whether bias affects minorities. Further, both studies relied on a nonrepresentative sample of faculty (those who agreed to participate) who knew their conduct was being analyzed, a factor known to alter behavior (Greenwald and Banaji, 1995), and the faculty made recommendations that would not impact them directly, diminishing the studies' external validity. Thus, although extensive research reviewed here relying on correlational, qualitative, and laboratory methodologies suggests that bias remains a problem in the Academy, these findings remain open to criticism from those who argue bias is no longer a significant problem (Heckman, 1998; Ceci and Williams, 2011; Stockdill and Danico, 2012).

Recent audit studies across a wide range of contexts outside of academia offer causal evidence with high external validity that discrimination continues to disadvantage minorities and women relative to White males with the same credentials. This research has shown that White job candidates receive a 50\% higher callback rate for interviews than identical Black job candidates (Bertrand and Mullainathan, 2004), Black and Latino job applicants with clean records are treated like Whites just released from prison (Pager, Western and Bonikowski, 2009), Blacks and Hispanics receive fewer opportunities to rent and purchase homes than Whites (Turner, et al., 2002; Turner and Ross, 2003), and women receive fewer interviews and offers than men for jobs in high-priced restaurants (Neumark, Bank, \& Van Nort, 1996). Together, these audit studies offer high experimental control and provide compelling evidence of discrimination in modern organizations. The one published audit study conducted to date within 
academia (using data from the same audit study analyzed in this paper) revealed that Black, Hispanic, Chinese, Indian, and female prospective $\mathrm{PhD}$ students receive less attention from faculty than White males (Milkman, Akinola, and Chugh, 2012), proving conclusively that bias remains a problem in the Academy.

\section{THE INFLUENCE OF ORGANIZATIONAL CHARACTERISTICS ON}

\section{DISCRIMINATION}

\section{Differences in Discrimination by Discipline}

Together, audit studies examining bias have primarily focused on documenting the existence of bias and measuring its magnitude but left open the critically important open question of how levels of bias may vary across environments. Extensive past social psychology research suggests that bias will vary as a function of the organizational context in which actors are embedded (for a review, see Yzerbyt and Demoulin, 2010). For instance, people's values, which vary across organizational contexts, have been shown to relate to stereotype activation (Moskowitz, Gollwitzer, Wasel, \& Schaal, 1999; Olson \& Fazio, 2002, 2004; Towles - Schwen $\&$ Fazio, 2003) and thus would be expected to affect bias, influencing the degree to which discrimination manifests itself across environments.

Tolbert and Oberfield (1991) theorize that heterogeneity in the gender composition of a university may result from multiple dynamics, including employer, constituency, and employee preferences, and find empirical support for the role of employer and constituency preferences on gender composition heterogeneity. Given that we study bias in academia, where there is substantial variability in the constituencies and cultures of academic disciplines, we would expect to see considerable heterogeneity in levels of bias across these differing constituencies and cultures - more than would be expected simply by chance. Demonstrating that such 
variability indeed exists provides a platform for then exploring sources of variability. Thus, our first and most basic hypothesis is as follows:

Hypothesis 1: Discrimination will vary significantly more than would be expected by chance across academic disciplines.

\section{Differences in Discrimination by Minority-group Representation}

A subsequent question of considerable theoretical interest is what characteristics of a discipline we would expect to exacerbate bias. Extensive past research suggests that individuals generally exhibit homophily and less bias against members of their own demographic group than against others (e.g., see McPherson, Smith-Lovin and Cook, 2001). Social identity theory suggests that people tend to categorize themselves as similar or different from others based on shared identity-relevant traits (Tajfel and Turner, 1986), such as race and gender (Cota and Dion, 1986; Porter and Washington, 1993; Frable, 1997). Shared identities draw individuals together, creating a perception of similarity, which leads to attraction (Byrne, 1971; Lincoln and Miller, 1979; Hogg and Terry, 2000), strong social ties (Ibarra, 1992), and better treatment of demographic in-group than out-group members. For instance, organizational members tend to prefer those who share their demographics when promoting, hiring, and mentoring others (Kanter, 1977; Ragins and McFarlin, 1990; Barker et al., 1999), including in professional sports (Price and Wolfers, 2010). This research suggests that minorities and women may exhibit less discriminatory behavior toward those who share their race or gender.

Further, greater representation of minorities and women may accrue other benefits to these groups, including higher work satisfaction, commitment, and reduced turnover (Williams and O'Reilly, 1998; Zatzick, Elvira and Cohen, 2003), likely due to the combined effects of homophily and the redefined social constructions of identity that can emerge in such contexts 
(Ely, 1995). While a small number of studies have hinted increases in the size of minority groups carry risks for minorities (e.g., Tolbert et al., 1995; McGinn and Milkman, 2013), most findings suggest that bias against women and minorities is likely to decline in settings where they are better represented. Thus, we hypothesize:

Hypothesis 2: Bias against women and minorities will be less severe in disciplines where they are better-represented.

\section{Differences in Discrimination by Faculty Pay}

We predict that faculty pay may also relate to bias against women and minorities. Recent psychological research has demonstrated that income strongly affects ethicality and generosity (Piff et al., 2010; Piff et al. 2012). Specifically, individuals higher in socioeconomic status make less ethical and less generous decisions in correlational studies (Piff et al., 2010; Piff et al. 2012). In addition, priming money experimentally also reduces ethicality and generosity (Vohs, Mead and Goode, 2006; Gino and Pierce, 2009); across a series of experiments, participants primed with money (relative to a neutral prime) volunteered significantly less time to helping others and donated significantly less money to a charitable fund for students in need (Vohs, Mead and Goode, 2006). In correlational studies, upper-class individuals were found to make more unethical driving decisions than lower-class individuals, violating traffic laws more frequently and placing pedestrians at greater risk, and further, wealthier individuals are more likely to lie, cheat, take valued goods from others, and endorse unethical behavior at work (Piff et al., 2012). In other words, across research using multiple methods (both studies that treat socioeconomic status as a trait and studies that explore the effects of priming money), the same negative association between money and generosity as well as ethicality arises. 
A key question is why both wealthier individuals and those primed to focus on wealth or abundance tend to be both less ethical and less generous. The dominant theory is that these individuals exhibit a reduced sense of empathy and connectedness with others. For instance, wealthier individuals demonstrate less empathetic accuracy than members of lower socioeconomic groups, and those induced to feel that they are higher in socioeconomic status (SES) than others perform worse at identifying emotions on pictures of faces (Krause, Côté and Keltner, 2010). In addition, in interactions with strangers, lower SES individuals engage more fully (e.g., through greater eye contact) than higher SES individuals (Kraus and Keltner, 2009). Recent research has also linked income to an endorsement of systems that perpetuate social inequality. Specifically, participants primed to think about money (versus those exposed to a neutral prime) were shown to (1) perceive the prevailing U.S. social system to be significantly more fair and legitimate, (2) be significantly more willing to rationalize social injustice, and (3) express a greater preference for group-based discrimination (Caruso et al., 2012). This research suggests a causal link between income and race and gender bias. If high incomes reduce egalitarianism, generosity, and racial tolerance, and increase support for systems that perpetuate social inequality, they may also produce discrimination.

Finally, the taste-based theory of discrimination in economics suggests that decision makers who prefer to hire and associate with a particular type of individual or group will be willing pay more for this preference, thus driving up the labor costs associated with members of this group (Becker, 1971). According to this perspective, only organizations with slack resources will have the financial capacity to act on their preference in hiring, suggesting that organizations with the resources to pay their faculty more also have the resources to engage in 
taste-based discrimination (Tolbert and Oberfield, 1991). Indeed, Tolbert and Oberfield (1991) found that universities with greater resources had lower percentages of women on their faculties.

Thus, we hypothesize the following:

Hypothesis 3: Bias against women and minorities will be more severe in disciplines and at universities where professors are better paid.

\section{Study Overview: The Field Experiment Approach}

We rely on a natural field experiment (Carpenter, Harrison and List, 2004) to test our hypotheses, an environment in which "subjects naturally undertake these tasks" and "do not know that they are in an experiment" (Carpenter, Harrison and List, 2004:6). Our methodology builds on past field experiments known as "audit studies" (e.g., Fix and Struyk, 1993; Bertrand and Mullainathan, 2004; Correll, Benard, and Paik, 2007; Pager, Western and Bonikowski, 2009; Rubineau and Kang, 2012), designed to measure bias by evaluating whether otherwise identical applicants for a valued outcome receive different treatment when race and/or gender-signaling information (such as the name atop a résumé or the appearance of someone acting out a script) is randomly varied (see Pager, 2007 for a discussion of this methodology). The natural field experiment method simultaneously offers ecological validity and experimental control (Pager, 2007; Quillian, 2006). In the examination of socially sensitive issues, particularly those related to bias, natural field experiments are particularly important because individuals are often unaware of or unwilling to reveal their biases when they recognize they are being studied (Greenwald and Banaji, 1995; Quillian, 2006). Further, natural field experiments eliminate selection bias in participant populations induced by allowing individuals to self-select into experiments. 
We report on new analyses of the data gathered in an experiment that was described previously in Milkman, Akinola, and Chugh (2012), which documented (1) the overall presence of bias in academia and (2) that decisions made for the future produce more discrimination than those made for today. We extend this research and work from prior audit studies examining discrimination in domains outside of academia in several important ways. First, rather than examining bias in the Academy in aggregate (as in Milkman, Akinola, and Chugh, 2012) or exploring bias primarily in one discipline or in the STEM disciplines (as other non-audit-studies set in academia have done), we examine discrimination discipline by discipline and university by university. This allows us to identify variation in bias across academic disciplines and to test hypotheses about where bias is concentrated rather than simply documenting the existence of bias. Second, we move beyond previous narrow audit studies of discrimination outside of academia against one underrepresented group (e.g., women, Blacks) to examine the mistreatment of a wider range of groups (women, Black, Hispanic, Chinese, and Indian students), thus better reflecting the demographic heterogeneity of modern organizations. Third, we examine bias at a pathway to the Academy, rather than at a gateway, highlighting the possibility that underrepresentation may be caused by factors influencing prospective applicants' decisions before they even apply for valued opportunities, beginning a process of cumulative disadvantage rarely captured in audit research.

\section{RESEARCH DESIGN AND METHODS}

\section{Study Participants}

We began by constructing a faculty subject pool. The primary criteria for selecting faculty participants was their affiliation with a doctoral program at one of the 259 universities on the U.S. mainland ranked in U.S. News and World Report's 2010 "Best Colleges" issue. From 
these universities, we identified 6,300 doctoral programs and approximately 200,000 faculty affiliated with those programs. We then randomly selected one to two faculty from each doctoral program, yielding 6,548 faculty subjects. ${ }^{2}$ From university websites, we collected each professor's email address, rank (full, associate, assistant, or n/a), gender, race (Caucasian, Black, Hispanic, Chinese, Indian, or Other; see Appendix for a discussion of our methods for classifying faculty race and gender), as well as university and department affiliations.

The faculty sample was selected in two different ways to facilitate a statistical examination of the impact of shared race between the student and professor. The first selection method involved identifying an entirely random (and thus representative) sample of 4,375 professors (87\% Caucasian, 2\% Hispanic, 1\% Black, 3\% Indian, 4\% Chinese, 3\% Other; 69\% Male). The second selection method involved over-sampling faculty who were not Caucasian, allowing us the necessary statistical power to test whether minorities are less (or more) biased toward students sharing their race. To examine whether the race and gender of faculty influence the degree to which bias is exhibited against minority and female prospective students, 2,173 additional minority faculty were picked for inclusion the study (29\% Hispanic, 21\% Black, 21\%

\footnotetext{
${ }^{2}$ The study was executed in two segments. In March 2010, a small pilot study was carried out, and in April 2010, the primary study was conducted. The pilot study conducted in March of 2010 included 248 faculty - one randomly selected tenure-track faculty member from 248 of the set of 259 universities (the 11 universities omitted from our pilot were omitted due to data collection errors). It also included just two fictional prospective doctoral students Lamar Washington and Brad Anderson. The primary study conducted in April of 2010 included a single tenure-track faculty member from each of the 6,300 doctoral programs at the U.S. universities, meaning we included an average of 24 faculty members per university. One affiliated, tenure-track faculty member was randomly selected from each doctoral program to participate, and each of the 20 prospective student names listed in Table 1 was included in the April 2010 study. The data from the pilot study did not differ meaningfully from those in the primary study thus we combined these data. Our results are all robust to including an indicator variable for pilot data, which is never significant.
} 
Indian, $29 \%$ Chinese, $68 \%$ Male), ${ }^{3}$ thus ensuring a sufficiently large sample for an analysis of same-race faculty-student pairs.

In all of our graphs and summary statistics, observations are sample weighted to account for the oversampling of minority faculty members in our study and unbalanced random assignment of faculty to conditions (same-race faculty-student pairs were over-represented in our random assignment algorithm, details in Experimental Procedures Section). Thus, all graphs and summary statistics can be interpreted as reporting results from a representative faculty sample (Cochran, 1963; see Appendix for a detailed discussion of our precise sample weighting methodology). Notably, however, all results and figures remain meaningfully unchanged if sample weights are removed.

\section{Experimental Stimuli and Procedures}

All emails from prospective students sent to faculty were identical except for two components. First, the race (Caucasian, Black, Hispanic, Indian, Chinese) and gender signaled by the name of the sender was randomly assigned (see Table 1 for details about the names used and their selection method; see Appendix for further details regarding our name selection methodology).

Insert Table 1 about here

Second, half of the emails indicated that the student would be on campus that very day, while the other half indicated that the student would be on campus one week in the future (next Monday), a change that was the focus of a previous paper analyzing the effects of temporal

\footnotetext{
${ }^{3}$ While an ideal sample would have had the same representation for each minority group, identifying Hispanic and Chinese faculty through automated methods was easier than identifying Indian and Black faculty, leading to different identification rates with our oversampling strategy.
} 
distance on discrimination (Milkman, Akinola and Chugh, 2012). The precise wording of emails received by faculty was as follows:

Subject Line: Prospective Doctoral Student (On Campus Today/[Next Monday])

Dear Professor [Surname of Professor Inserted Here],

I am writing you because I am a prospective doctoral student with considerable interest in your research. My plan is to apply to doctoral programs this coming fall, and I am eager to learn as much as I can about research opportunities in the meantime.

I will be on campus today/[next Monday], and although I know it is short notice, I was wondering if you might have 10 minutes when you would be willing to meet with me to briefly talk about your work and any possible opportunities for me to get involved in your research. Any time that would be convenient for you would be fine with me, as meeting with you is my first priority during this campus visit.

Thank you in advance for your consideration.

Sincerely, [Student's Full Name Inserted Here]

Emails were queued in random order and designated to be sent at 8a.m. in the time zone corresponding to the relevant faculty member's university. To minimize the time faculty spent on our study, we prepared (and promptly sent) a series of scripted replies cancelling any commitments from faculty that had been elicited and curtailing future communications. See Appendix for details regarding the human subjects protections in this study.

Assignment of faculty to experimental conditions was stratified by their gender, race, rank, and time zone (EST, CST, MST and PST) to ensure balance on these dimensions across conditions. In addition, as described above, we ensured that same-race faculty-student pairings were overrepresented to allow for a statistically powered examination of the effects of matched race. First, two-thirds of the Caucasian faculty from the representative sample of 4,375 professors, and all non-Caucasian faculty from this representative sample, were randomly assigned to one of the experimental conditions in our study with equal probability, except that no 
professors in this group were assigned to receive an email from a student who shared their race. Then, all oversampled non-Caucasian faculty $(\mathrm{N}=2,173)$ as well as the final third of Caucasian faculty $(\mathrm{N}=1,294)$ were assigned to receive emails from students of their race (e.g., oversampled Hispanic faculty received emails from Hispanic students). For these participants, only the gender of the prospective student and the timing of the student's request (today vs. next week) were randomized.

In total, 6,548 emails were sent from fictional prospective doctoral students to the same number of faculty. Experimental cell sizes varied somewhat (depending on our identification rate, oversampling faculty to allow for statistically meaningful rates of matched-race facultystudent pairs, and as a result of our pilot study, which only included Caucasian Male and Black Male students); cell size by prospective student race and gender were as follows: Caucasian Male $(\mathrm{N}=791)$, Caucasian Female $(\mathrm{N}=669)$, Black Male $(\mathrm{N}=696)$, Black Female $(\mathrm{N}=579)$, Hispanic Male (N=668), Hispanic Female $(\mathrm{N}=671)$, Indian Male $(\mathrm{N}=572)$, Indian Female $(\mathrm{N}=578)$, Chinese Male $(\mathrm{N}=661)$, and Chinese Female $(\mathrm{N}=663)$.

\section{Supplementary Data}

Data about academic disciplines. To categorize the academic disciplines of faculty in our study, we relied on categories created by the U.S. National Center for Education Statistics. This center conducts a National Study of Postsecondary Faculty (NSOPF) at regular intervals (most recently in 2004) and classifies faculty into one of 11 broad and 133 narrow academic disciplines (see: http://nces.ed.gov/surveys/nsopf/). The NSOPF survey results were available as summary statistics describing various characteristics of survey respondents both by broad and narrow academic discipline. 
A research assistant examined each faculty member's academic department and classified that faculty member into one of the NSOPF's 11 broad and 133 narrow disciplinary categories. Of the 6,548 faculty in our study, 29 worked in fields that either could not be classified or identified and were thus dropped from our analyses. The remaining professors were classified into one of 10 of the NSOPF's 11 broad disciplinary categories (the category with no representation was Vocational Education) and into one of 109 of the NSOPF's 133 narrow disciplinary categories (see Appendix Table A2 for a list of categories).

We examine how several variables collected by the NSOFP's most recent survey by narrow academic discipline affect levels of discrimination in our study: the percentage of faculty in a discipline who are women $(M=38 \%$; S.D. $=21 \%)$ and members of different racial groups (Caucasian ( $\mathrm{M}=85 \%$; S.D.=8\%), Black $(\mathrm{M}=6 \%$; S.D.=4\%), Hispanic $(\mathrm{M}=3 \%$; S.D. $=3 \%)$ and Asian (M=10\%; S.D.=8\%)), the percentage of Ph.D. students in a discipline who are members of different racial groups (Caucasian ( $M=76 \%$; S.D.=4\%), Black ( $M=10 \%$; S.D.=3\%), Hispanic $(\mathrm{M}=7 \%$; S.D. $=2 \%)$, and Asian $(\mathrm{M}=7 \%$; S.D. $=2 \%),{ }^{4}$ and the average nine-month faculty salary in a discipline.

Data about universities. For each of the national U.S. universities ranked in U.S. News and World Report's "Best Colleges" issue, U.S. News reports numerous facts describing the university during the 2009-2010 academic school year that were merged with our experimental data. First, each school's ranking was included (1-260). Second, U.S. News reports on whether each school is a private or public institution $(37 \%$ of those in our sample are private; $63 \%$ are public). Third, U.S. News reports on the demographic breakdown of the undergraduate student

\footnotetext{
${ }^{4}$ Note that the NSOFP does not include statistics about the percentage of students who are female nor does the NSOFP provide statistics on Chinese and Indian faculty or student separately - they report on a single "Asian" category.
} 
body (female ( $\mathrm{M}=52 \%$; S.D. $=9 \%)$, Caucasian $(\mathrm{M}=68 \%$; S.D. $=19 \%)$, Black $(\mathrm{M}=11 \%$;

S.D. $=16 \%)$, Hispanic $(M=8 \%$; S.D. $=9 \%)$, and Asian $(M=9 \%$; S.D. $=9 \%))$ as well as the percentage of a university's faculty who are female ( $M=38 \%$; S.D. $=8 \%)$. We rely on each these university characteristics in our analyses of faculty response rates to emails from white males versus women and minorities.

\section{Statistical Analyses}

Regression specifications. To study the effects of various potential moderators (i.e., department and university characteristics) on faculty members' level of responsiveness to emails from women and minorities in aggregate relative to Caucasian males, we use the following ordinary least squares (OLS) regression specification:

$$
\begin{aligned}
& \text { response_received }_{i}=\alpha+\beta_{1} * \text { moderator }_{i}+\beta_{2} * \text { min-fem }_{i} * \text { moderator }_{i}+\beta_{3} * \text { black }_{i}+\beta_{4} * \text { hispanic }_{i}+ \\
& \beta_{5}{ }^{*} \text { indian }_{i}+\beta_{6}{ }^{*} \text { chinese }_{i}+\beta_{7} * \text { female }_{i}+\beta_{8}{ }^{*} \text { black }_{i}^{*} \text { female }_{i}+ \\
& \beta_{9} * \text { hispanic }_{i}^{*} \text { female }_{i}+\beta_{10} * \text { indian }^{*} \text { female }_{i}+\beta_{11} * \text { chinese }_{i}^{*} \text { female }_{i}+\theta^{*} X_{i}
\end{aligned}
$$

where response_received ${ }_{i}$ is an indicator variable that takes on a value of one when faculty

member $i$ responded to the email requesting a meeting and zero otherwise, ${ }^{5} \mathrm{~min}_{\mathrm{fem}}$ is an

indicator variable that takes on a value of one when a meeting request is from a racial minority or

female student and a value of zero otherwise, moderator $_{i}$ is a (standardized) variable that

corresponds to a given moderator of interest (e.g., percentage of faculty in a given narrow

discipline who are female), black $_{i}$ is an indicator variable taking on a value of one when a

\footnotetext{
${ }^{5}$ Nearly all faculty responses to students in our study conveyed a willingness to offer assistance or guidance, but due to scheduling constraints, many encouraging faculty responses did not include an immediate offer to meet with the student on the requested date. In previously reported analyses of our data (Milkman, Akinola and Chugh, 2012), it was determined that all bias against women and minorities in this experiment occurs at the email response stage. Specifically, faculty respond to (and therefore also agree to meet with) women and minorities at a significantly lower rate than Caucasian males. However, once a faculty member responds to a student, no additional discrimination is observed on the decision of whether to respond affirmatively or negatively. In other words, all discrimination observed on the decision of whether to meet with a student results from e-mail non-responses, which is thus the outcome variable on which we focus our attention here.
} 
meeting request comes from a Black student and zero otherwise, and so on for other race/gender indicator variables, $X_{i}$ is a vector of other control variables, and $\theta$ is a vector of regression coefficients. $X_{i}$ includes indicators for whether the professor contacted was: Black, Hispanic, Indian, or Chinese; a member of another minority group besides those listed previously; male; an assistant, associate, or full professor; another rank besides assistant, associate or full professor; the same race as the student emailing and Black; the same race as the student emailing and Hispanic; the same race as the student emailing and Indian; the same race as the student emailing and Chinese; and asked to meet with the student today (as opposed to next week). Based on the finding from previous research using this audit study data that discrimination primarily arises in decisions made for the future (Milkman, Akinola and Chugh, 2012), we also control for the interaction between the indicator for a student being on campus today and $m i n-f_{e} m_{i}$. Finally, we control for the contacted professor's university's (standardized) U.S. News 2010 ranking.

To separately examine the treatment of each minority group studied, we rely on the regression specification described above but replace the predictor variable $\min -\mathrm{fem}_{i}$ with nine indicators for the nine race and gender groups studied besides Caucasian males (e.g., a dummy variable for Caucasian female students, for Black male students, etc.; Caucasian males are the omitted category).

We estimate the equation described above using an OLS regression and cluster standard errors by a faculty member's academic discipline and university affiliation. We rely on OLS regression models to evaluate this data for ease of presentation (further, Ai and Norton (2003) have demonstrated that standard errors on interaction terms in logistic and probit regressions can be unreliable). However, our findings are nearly identical if we instead rely on logistic regression models (see Appendix). 
Our primary regression results are presented without sample weights but instead including controls for the various variables used to select our sample and allocate assignment to conditions. Including these controls serves the same purpose as including sample weights because they account for our experiment's unbalanced random assignment (Winship and Radbill, 1994). Thus, all regression results can be interpreted as if the population studied were a representative sample of faculty. All reported regression results are robust to the inclusion of sample weights and one-way clustering of standard errors.

\section{RESULTS}

\section{Descriptive Statistics}

We examine whether a given email generates a reply from a given professor in our experiment within one week, by which point responses had essentially asymptoted to zero (with $95 \%$ of responses received within 48 hours and just $0.4 \%$ arriving on the seventh and final day of our study). The final sample of faculty included $43 \%$ full professors, $27 \%$ associate professors, $25 \%$ associate professors, and 5\% professors who were either emeritus or of unknown rank. Table 2 shows descriptive statistics for our faculty participant sample. Sixty-seven percent of the emails sent to faculty from prospective doctoral students elicited a response. All underrepresented groups studied experienced lower response rates than Caucasian males, as reported in a previous paper (Milkman, Akinola and Chugh, 2012). Notably, as Table 2 shows, the raw average response rate to Caucasian males is directionally higher than the raw average response rate to minorities and females (the "discriminatory gap") in all but one broad discipline (fine arts) and is considerably larger at (higher-paying) private schools than at public schools (private schools pay $\$ 34,687$ higher yearly salaries, on average; Byrne, 2008). 


\section{Multivariate Analyses}

Bias as a function of broad academic discipline (Hypothesis 1). In regression

analyses, we find that a significant (rather than merely directional) discriminatory gap is present in all but two disciplines in the Academy. Figure 1a plots coefficient estimates and their associated standard errors from OLS regressions, which indicate the magnitude and significance of the bias (referred to as "the discriminatory gap") in each broad academic discipline.

Insert Figure 1 about here

These are statistical estimates (from regression equations) of the same gaps presented in Table 2 as raw summary statistics. Specifically, Figure 1a plots the coefficient estimates from a regression in which an email response is predicted by interactions between (1) an indicator for whether a student is a minority or female and (2) indicators for each broad academic discipline studied (e.g., business, fine arts, etc.). The regression coefficients on these interaction terms capture the predicted discriminatory gap for each discipline. These OLS regressions include the full vector of control variables, $X_{i}$, described in the Regression Specifications section, indicators for student race and gender, and indicators for a professor's discipline. Standard errors are clustered by student name.

Figure $1 \mathrm{~b}$ again plots the discriminatory gap based on coefficient estimates from OLS regressions using the same specifications, but breaks out the race/gender of the student to show levels of bias against each group studied (both effects that are significant and those that are directional but not significant; see Appendix for a nearly identical graph plotting raw summary statistics). Figure $1 \mathrm{~b}$ demonstrates that the regression results plotted in Figure 1a are not driven 
by the treatment of a particular race or gender of student, although, notably, students of Asian descent experience particularly pronounced bias (contrary to what past research on stereotypes of Asians as "model minorities" might predict, Lin et al., 2005). Seven of the ten discipline-bydiscipline estimates of the "discriminatory gap" in the treatment of minorities and females relative to Caucasian males in Figure 1a are statistically significant (p's $<0.05)$, and an eighth is marginally significant (social sciences; $\mathrm{p}<0.10$ ), indicating that in all broad disciplines except health sciences and humanities, women and minorities are ignored at rates that differ from Caucasian male students.

Notably, the regression analyses presented in Figure 1a and the summary statistics presented in Table 2 suggest that bias may play a greater role in impeding female and minority careers in certain disciplines than in others. Specifically, a Wald Test of the hypothesis that the discriminatory gaps estimated across disciplines are jointly equal to one another indicates that our coefficient estimates of the size of the discriminatory gap by discipline differ significantly more from one another than would be expected by chance $(\mathrm{F}=7.63 ; p<0.001)$, supporting Hypothesis 1. For example, bias against women and minorities is significantly higher in disciplines such as business and education than in the social sciences, humanities, and natural sciences (for all six paired comparisons, p's $<0.05$ ).

Importantly, the differences in bias faced across disciplines across the nine female and minority groups studied are highly correlated. The Cronbach's alpha assessing the "scale reliability" of the bias detected against these nine different groups (with data points corresponding to bias levels in each of the ten disciplines studied from Figure $1 \mathrm{~b}$ ) is 0.87 . Of the 36 paired correlation coefficients produced by comparing columns from Figure 1b, 94\% (or all but two) are positive, and the average correlation is 0.47 (median correlation $=0.52$ ). Thus, 
combining women and minorities to examine these students' treatment together in many of our analyses (while also presenting results broken down group by group) appears appropriate.

Our remaining analyses of bias across disciplines examine bias at the level of a professor's narrow academic discipline (e.g., accounting, chemistry, music; see NSOFP, 2004 and Appendix Table A2 for discipline classifications), where we have 89 disciplines to examine rather than $10 .^{6}$ By looking at levels of bias across these 89 , narrower disciplinary categories, we will have a sufficiently large sample of disciplines to investigate our hypotheses ( $\mathrm{H} 2$ and $\mathrm{H} 3)$ regarding what moderates the size of the discriminatory gap.

\section{Representation of Females and Minorities as a Moderator of Bias (Hypothesis 2).}

As described in the Regression Specifications section, we estimate a series of regressions to explore whether differences in bias across narrow disciplines or universities are correlated with variance in the representation of women and minorities. Said simply, we test whether disciplines or universities with more minorities (in aggregate, or from specific groups) and women are less likely to show bias against these groups (H2).

In Table 3, Model 1, to determine whether differences in bias across narrow disciplines are correlated with variance in the representation of minorities or females in those disciplines, we rely on the regression specification described in the Regression Specifications section, including moderator variables that capture the percentage of female, Black, Hispanic, and Asian faculty and Black, Hispanic, and Asian graduate students in each professor's narrow discipline according to the 2004 NSOFP survey.

Insert Table 3 about here

\footnotetext{
${ }^{6}$ Faculty in our sample represented 109 of the 133 narrow NSOPF disciplines. Twenty of the 109 narrow disciplinary categories in which faculty in our study were classified were disciplines for which the 2004 NSOFP survey reported no data, leaving us with 89 analyzable narrow disciplines.
} 
As the Regression Specifications section details, in analyses that disaggregate women and minorities, we both include these moderators as main effects and interact these variables with an indicator for an email sent by a student in the relevant demographic group (female, Black, Hispanic, or Asian). Appendix Table A1 describes each of the primary predictor variables included in Table 3 (and in Table 4).

For example, in Model 1, the first predictor listed is the variable "Faculty \% Black," and the coefficient estimate on this predictor captures the main effect of a one standard deviation increase in the percentage of black faculty at a university on the likelihood of receiving a response. The second predictor listed is the interaction term "(Fac\%Black) x (Black Student)," which represents the effect of a one standard deviation increase in the percentage of black faculty at a university on a black student's likelihood of receiving a response. Model 1 shows that none of these interaction terms significantly predicts faculty responsiveness, although Asian students are marginally less likely to receive a response in fields with more Asian graduate students. Model 2 shows that aggregating minority groups together by combining Black, Hispanic, and Asian faculty into a single "minority faculty" group and similarly combining minority $\mathrm{PhD}$ students produces the same null results. Together, these results suggest that representation (as captured by our demographic composition variables) is not predictive of bias.

Although this finding may seem surprising, our modeling strategy already accounts for any direct benefits of a student reaching out to a faculty member sharing his or her race or gender by including indicator variables accounting for matched race and gender. Thus, the only remaining pathway through which representation could impact response rates is by affecting the bias towards women and minorities shown by faculty who do not share a student's race or 
gender. However, across all models in Table 3, we also observe no benefits to women of contacting female faculty, consistent with recent work by Moss-Racusin et al. (2012). Similarly, consistent with findings presented in Milkman, Akinola, and Chugh (2012), only Chinese students experience significant benefits from contacting same-race faculty (the effect is marginally significant for Indian students contacting Indian faculty, and other groups do not benefit at all; see Table 3). Thus far, we find essentially no evidence that bias against women and minorities is lower in disciplines with higher female and minority representation.

Before turning away from the possibility that faculty in areas with greater representation of women and minorities are less biased against women and minorities, we look at additional measures capturing the representation of women and minorities across 247 different universities in our sample using available data on minority and female representation at these institutions. In Table 3, Model 3 we add moderator variables to our model for the proportion of Blacks, Hispanics, Asians, ${ }^{7}$ and females in a university's undergraduate population and for the proportion of faculty at a university who are female, as reported by U.S. News (U.S. News and World Report, 2010). Again, we find no relationship between representation and discrimination. In fact, the only significant relationship we detect is a reduction in the rate of response to Hispanic students at universities with higher Hispanic representation - a result that goes in the opposite of the direction one would expect if greater representation were associated with reduced bias. Model 4 shows that aggregating minority groups by combining Black, Hispanic, and Asian undergraduates into a single "minority undergraduate" group produces the same null results. These analyses thus provide further evidence that faculty bias is unaltered by the proportion of women and minorities in a professor's work environment.

\footnotetext{
${ }^{7}$ US News provides statistics about a single category of "Asian" students and provides no statistics on the ethnic breakdown of university faculty.
} 
Pay as a moderator of bias (Hypothesis 3). In examining summary statistics from our data, we observe an impressive correlation (with insufficient sample size to reach statistical significance, $\mathrm{N}=10$ ) between average faculty salary and the size of the discriminatory gap by broad discipline $\left(\mathrm{r}_{\text {regression-estimated-discriminatory-gap,pay }}=0.4\right)$, consistent with our third hypothesis. Average nine-month salaries reported in the 2004 NSOFP survey by narrow discipline in our sample varied from $\$ 30,211$ (Dance) to $\$ 118,786$ (Medicine) with a standard deviation of $\$ 13,265$, and Figure 2 reveals a strong correlation between average salary by narrow discipline and the size of the discriminatory gap in our raw data as well, supporting Hypothesis 3.

Insert Figure 2 about here

In a regression exploring the relationship between salary and discrimination shown in Table 4, Model 5, we find that a $\$ 13,265$ salary increase predicts a significant, five percentage point drop in the response rate to minorities and females $(\mathrm{p}<0.01)$, but there is no predicted change in the response rate to Caucasian males $(p=0.70)$. In other words, the predicted discriminatory gap widens by five percentage points for every standard deviation increase in a discipline's salary. Notably, if we disaggregate the nine separate female and minority groups studied, greater bias is observed in higher-paid disciplines for every group. Specifically, the effect of a one standard deviation increase in salary on the size of the discriminatory gap for each student group studied is as follows: Caucasian F: $+2.9 \%$ (S.E. $=2.6 \%$ ); Black M: $+3.8 \%$ $($ S.E. $=2.4 \%)$; Black F: $+4.9 \%$ (S.E. $=2.9 \%)$; Hispanic M: $+2.2 \%($ S.E. $=2.5 \%)$; Hispanic F: $+4.7 \%$ $($ S.E. $=2.5 \%)$; Chinese M: $+4.9 \%$ (S.E. $=2.9 \%)$; Chinese F: $+4.6 \%($ S.E. $=2.5 \%)$; Indian M: $+6.7 \%$ $($ S.E. $=2.6 \%)$; and Indian F: $+5.5 \%($ S.E. $=2.2 \%)$. 
Insert Table 4 about here

In addition to espousing different values than their public counterparts, private institutions also pay higher salaries $(\$ 34,687$ higher on average; Byrne, 2008); therefore, we investigate whether levels of bias vary between public $\left(\mathrm{N}_{\text {public }}=163\right)$ and private universities $\left(\mathrm{N}_{\text {private }}=96\right)$. First, we find a meaningful difference in bias by institution type, controlling for a university's prestige with its U.S. News ranking (2010). The regression-estimated size of the discriminatory gap experienced by minorities and females is 16.1 percentage points at private schools (std. err. $=2.8 \%$ ) and 6.2 percentage points at public schools (std. err. $=3.2 \%$ ), a significant difference $(\mathrm{p}<0.001)$. Figure 3 plots OLS regression estimates and their associated standard errors from analyses of the magnitude and significance of bias for each race/gender group studied, highlighting that the public-private gap is persistent across all groups included in our research (again controlling for U.S. News ranking; note that these OLS estimates of bias are nearly identical to raw summary statistics shown in the Appendix).

Insert Figure 3 about here

In Table 4, Model 6 presents the results of regression analyses testing the effects of faculty pay by discipline on the size of the discriminatory gap. Here, we find that the predicted discriminatory gap is 15 percentage points larger at private institutions than at public institutions $(\mathrm{p}<0.001)$

Interestingly, Models 7 and 8 in Table 4 highlight two measures of status that are unrelated to bias in our sample. Model 7 reveals that a school's U.S. News ranking is not significantly correlated with the school's level of bias $(p=0.91)$. Model 8 shows that a faculty 
member's academic rank (associate, assistant, or full professor) is also an insignificant predictor of bias $(\mathrm{p}=0.94)$

\section{DISCUSSION}

Through a field experiment set in academia, we show experimentally that nearly every academic discipline exhibits race and gender bias at a key pathway to the Academy. We also demonstrate that bias varies more than would be expected by chance across different broad academic disciplines. And we explore characteristics shared by the disciplines most biased against women and minorities, offering insights into factors that may contribute to the widespread underrepresentation of women and many minority groups. In exploring the causes of this variation, we find no relationship between representation in a discipline (or university) and levels of bias, contradicting our second hypothesis. However, we do find a robust relationship between pay and bias, whereby faculty in higher-paid disciplines are less responsive to minority and female students than to Caucasian males. We also find significantly greater bias against every female and minority student group studied at private universities (which pay higher salaries) than at public universities.

Our study is the first to explore bias experimentally throughout the Academy not only at an early career stage but also (a) with a representative faculty sample and (b) with a subject pool unbiased by the prospect of being observed by researchers. These findings offer evidence that bias affects female and minority prospective academics seeking mentoring at a critical early career juncture in the fields of business, education, human services, engineering, and computer sciences, natural/physical sciences, and math, and marginally in the social sciences. In addition, bias harms Caucasian males in the fine arts. Notably, the magnitude of the bias we find is quite large. In the most discriminatory discipline we observe in our study - business - minorities and 
females seeking guidance are ignored at 2.6 times the rate of Caucasian males, and even in the least discriminatory academic discipline - the humanities (where bias does not reach statistical significance) - minorities and females are still ignored at 1.3 times the rate of Caucasian males. Such differences in treatment could have meaningful career consequences for individuals and meaningful societal consequences as well.

Further, our findings reveal how seemingly small, daily decisions made by faculty about guidance and mentoring can generate bias that disadvantages minorities and females. These “micro-inequities" (Rowe, 1981; 2008) and "micro-aggressions" (Sue, 2010) are often on the pathways that lead to (or emerge after) gateways. It is important to recognize that bias, even if unintended, in the way faculty make informal, ostensibly small choices can have negative repercussions (Petersen, Saporta, and Seidel, 2000), especially as seemingly small differences in treatment can accumulate (Valian, 1999; DiPrete and Eirich, 2006).

Our research contributes to the literature on discrimination in organizations broadly and in academia specifically in several important ways. First, we contribute to past research exploring bias in academia by answering the critical question of whether bias in the sciences extends beyond women (Steinpreis, Andres, and Ritzke., 1999; Moss-Racusin et al., 2012) to minorities. Indeed, consistent with findings from previous correlational and qualitative research, we find that minorities are discriminated against in the STEM fields, likely contributing to the underrepresentation of Black and Hispanic faculty in these disciplines (National Science Foundation, 2009). Second, we answer the question of where in academia race and gender bias is most severe, revealing that the fields of business and education exhibit the greatest bias and that the humanities and social sciences exhibit the least. Finally, and most relevant to organizational scholars, we explore characteristics shared by disciplines that are most biased against women and 
minorities. We find that higher pay is correlated with greater bias (both within disciplines and across lower- vs. higher-paying [public vs. private] institutions); somewhat surprisingly, higher representation of women and minorities in a discipline or university does not protect against bias. Next, we discuss possible explanations for these findings and provide further data supporting the hypothesis (H3) that a higher income goes hand in hand with more extreme discrimination.

\section{Pay and Discrimination}

We have hypothesized and found evidence supporting the hypothesis that discrimination is greater in higher-paid professional environments, basing this hypothesis on past research showing that high incomes reduce egalitarianism and generosity (Piff et al., 2010; Piff et al. 2012; Caruso et al., 2012). To further test this possibility, we conducted a follow-up study to supplement our field experiment. We recruited 128 participants through Amazon's Mechanical Turk to complete a five minute online survey in exchange for $\$ 0.25$ (63 male, 65 female; $\mathrm{M}_{\mathrm{age}}=$ 33.2, S.D.age $=11.7 ; 73 \%$ Caucasian). Six items from the Attitudes Towards Blacks Scale (Brigham, 1993) were first presented to participants (e.g., "Black and white people are inherently equal"). Participants were asked to indicate the extent to which they agreed with each statement on a scale ranging from 1 (strongly disagree) to 7 (strongly agree) $(\mathrm{M}=5.53$; S.D. $=1.63$; Cronbach's alpha $=0.82$ ). Next, on a separate page, participants responded to questions assessing attitudes about women's rights and racial policy (Pratto, Sidanius, Stallworth and Malle, 1994), such as "Which of the following objects, events or statements do you have positive or negative feelings towards?" with a response scale ranging from 1 (very negative) to 7 (very positive). They were then presented with four items related to women's rights (e.g., "Equal pay for women") $(\mathrm{M}=6.16$; S.D. $=1.13$; Cronbach's alpha $=0.71)$ and seven related to racial policy (e.g., "Helping minorities get a better education") $(\mathrm{M}=4.96$; S.D. = 1.92; 
Cronbach's alpha $=0.83$ ). Finally, participants were asked a series of questions about their demographics. Social class was measured in three different ways, all following previous research by Kraus and Keltner (2009). Participants indicated their highest level of educational achievement and their annual household income. They also completed an online version of the MacArthur Scale of subjective social status (SSS; Adler et al., 2000). This involved viewing a picture of a ladder with 10 rungs representing people with different levels of education, income, and occupational status and selecting the rung where they felt they stood relative to others in their community.

Across the three scales (and 17 items) designed to measure discriminatory attitudes, the Cronbach's alpha was $0.89(\mathrm{M}=5.44 ;$ S.D. $=1.72)$. Thus, we standardized and summed these 17 items to create a single measure of bias (with higher scores indicating less bias toward women and minorities). We test the hypothesis that bias is higher among participants with higher income by examining the correlation between self-reported income and bias. There is a significant and negative correlation between our measure of tolerance for women and minorities and selfreported income $(r=-0.22 ; \mathrm{p}=0.012)$. Further, when we standardize and sum our three measures of social class (income, education, and SSS), we find a significant, negative correlation between this social class index and our bias index $(r=-0.24 ; p=0.007)$. Separate explorations of the nine possible correlations between our three separate bias scales and our three separate measures of social class reveal that each correlation is in the predicted direction: higher social class is always associated with greater bias. In short, we find that those with higher income and higher social class exhibit significantly more bias against women and minorities.

Taken together, these results provide support for the possibility that those with higher incomes are more biased than those with lower incomes against women and minorities. If higher 
incomes reduce racial tolerance and increase support for systems that perpetuate social inequality, they may also produce discrimination.

Importantly, however, there are alternative explanations for the finding that higher-paid faculty and faculty at private schools are more biased. One possibility is that the populations of faculty who choose (or are selected) to work in higher-paid fields and at private (versus public) institutions have different values and priorities than other faculty. The very fact that levels of underrepresentation vary across disciplines highlights that different types of people fill the faculty ranks in different areas of the Academy. For instance, women pursue careers in math and science at markedly lower rates than men (Handelsman et al., 2005). Further, individuals select unevenly into disciplines on many other dimensions besides race and gender (e.g., mathematical ability, vocabulary, social skills); therefore, it may be that more discriminatory individuals prefer to work in higher-paid fields and at private institutions. While we cannot rule out faculty selection as an explanation for any of our findings, it is not at all clear why higher-paid disciplines would attract less egalitarian and more discriminatory faculty, and future research exploring this question is needed.

Another possibility is that the treatment of faculty differs across institutions and schools. For instance, differing university policies between private and public institutions might be responsible for the differences detected in bias across these two types of schools. Similarly, disciplines with higher pay might tend to instill different values in their faculty, provide them with different training, or institute different policies than those with lower pay, altering observed levels of bias. Considerable past research, particularly in social psychology, has emphasized the power of one's situation to influence behavior (Ross and Nisbitt, 1991). While we again cannot 
rule out the possibility that policies or values drive differential discrimination as a function of faculty pay, it is again not clear why such a link would exist.

Multiple processes may have worked in concert to produce the bias we detect, or bias may be driven by another variable correlated with pay. However, our findings contribute to a growing body of theory and research linking money and egalitarianism and importantly point toward income as a previously unexplored moderator of race and gender bias.

\section{Representation, Shared Characteristics, and Discrimination}

We have reported two counterintuitive findings: 1) representation does not reduce bias and 2) there are no benefits to women of contacting female faculty nor to Black or Hispanic students of contacting same-race faculty. These results are consistent with past research showing that stereotypes are firmly held even by members of the groups to which those stereotypes apply (Nosek, Banaji, and Greenwald, 2002) and that female scientists are just as biased against female job applicants as male scientists (Moss-Racusin et al., 2012). Importantly, our findings suggest that although past work has shown benefits accruing to females and minorities from increases in female and minority representation in a given organization, these benefits may not be the result of reduced bias but rather of other mechanisms, such as the availability of role models or changes in culture associated with increasing demographic diversity. Our work reveals that when a field boasts impressive representation of minorities and women within its ranks, this cannot be assumed to eliminate or even necessarily reduce bias. More specifically, no discipline, university, or institution in general should assume that its demographic composition will immunize it against the risk of exhibiting discrimination.

Moreover, it would be inaccurate to assume that the bias we detect is not contributing to the under-representation of women and minorities at the doctoral and faculty ranks. As 
extensive past research has highlighted, the under-representation of women and minorities in nearly every academic discipline can be attributed to bias and other forces, including isolation, availability of mentors, preferences, lifestyle choices, occupational stress, devaluation of research conducted primarily by women and minorities, and token-hire misconceptions (Menges and Exum, 1983; Turner, Myers and Creswell, 1999; Correll, 2001; Croson and Gneezy, 2009; Ceci et al., 2011). Ultimately, our results document that bias remains a problem in academia and highlight where this particular contributor to underrepresentation most needs attention.

\section{Implications for Organizations}

It has been suggested that changing the attitudes of minorities and women toward challenging career paths and making the work environment more accommodating of varied cultures and lifestyles will increase diversity (e.g. Rosser and Lane, 2002), yet our findings highlight that these efforts will likely be insufficient to entirely close the representation gap. In addition to critically important steps to increase diversity on the "supply side," our research suggests that achieving parity will also require tackling bias on the "demand side."

Natural approaches to combating bias in organizations focus on altering procedures at formal gateway decision points. Our findings underscore the need for attention to the possibility of bias at every stage when members of organizations make decisions about how to treat aspiring colleagues, including informal interactions that organizations are unlikely to monitor but may be able to influence (Rowe, 1981; 2008). Thus, our findings suggest that systems to prevent discrimination in formal processes (such as hiring and admission in academia) should be partnered with systems to nudge decision-makers away from the unintended biases that affect their informal decisions. 
Additionally, while our study contributes to our understanding of discrimination in organizations broadly, policy makers and university leaders should be aware of the particular need for academic programs designed to combat bias, particularly in high-paying disciplines and at private universities. Increasing female and minority representation among university faculty and graduate students is associated with higher educational attainment and engagement for female and minority students, respectively, sending an important signal to students about who can climb to the highest levels of the academic ladder (Rask and Bailey, 2002; Trower and Chait, 2002; Bettinger and Long, 2005; Griffith, 2010; Sonnert, Fox and Adkins, 2007).

\section{Limitations and Future Directions}

Our study raises important unanswered questions for future research. For example, prevailing theories regarding the causes of discrimination distinguish between taste-based discrimination, which refers to race or gender animus as a motivation for discrimination (see Becker, 1971), and statistical discrimination, which assumes that a cost-benefit calculus devoid of animus underlies observed discrimination (Phelps, 1972; Fernandez and Greenberg, 2013). Both theories of discrimination assume that individuals consciously discriminate (Bertrand, Chugh, and Mullainathan, 2005), yet our research design was intended to capture both conscious and unconscious discrimination. Unfortunately, our experimental design prevents us from disentangling whether statistical, taste-based, implicit, or explicit discrimination underlies the bias we detect, and future research examining these questions would be valuable.

It is also important to note that we focus narrowly on a specific pathway to the Academy that is just one moment in the lengthy process in which prospective academics engage. Further, we examine just one type of organization where bias may hinder career progress. Future audit studies investigating bias in academic and non-academic settings would be valuable. Likewise, 
examining varied pathways (and gateways) and documenting the cumulative impact of similar moments on career outcomes would be worthwhile.

Future work might adopt a multi-level perspective that studies the relationships between pathway processes, organizational demography, and individual careers (Lawrence and Tolbert, 2007). Specifically, the relationship between representation and bias that we hypothesized likely would benefit from further investigation to fully explicate if, when, and how organizational demography and discrimination are related. Additional research might also consider how research on careers and occupations relates to gateways and pathways; for example, when are experiences on pathways more or less likely to influence career choices?

Further, future research could explore the treatment of additional groups. We did intentionally include intersectional identities in our study design based on research highlighting that the experiences of minority women are frequently the product of intersecting racial and gender inequities (e.g. Crenshaw, 1991; McCall, 2005). Future research on the dynamics and consequences of intersectionality as it relates to bias in academia is needed.

Finally, it is important to acknowledge the limitations associated with using names to signify race. For instance, many foreign nationals use anglicized names, yet in our study we intentionally selected non-anglicized names to reduce racial ambiguity. Further, it is important to note that in addition to race, names may signify numerous features (e.g., class, birthplace, linguistic proficiency), making it difficult to single out race as the sole source of the discriminatory behavior we observed in our study. Future studies should consider using varied methods (i.e., photographs) to signify race in an effort to examine the extent to which our findings replicate across stimuli.

\section{CONCLUSION}


Ultimately, the goal of this research is to advance our understanding of the barriers that stand in the way of achieving greater representation of women and minorities in organizations where they are currently underrepresented. The continued underrepresentation of women and minorities means that many of the most talented individuals with the potential to make contributions to organizations and inspire the next generation of employees and students may not be progressing on the pathway to achieve their potential. By addressing what happens before people enter academia, we hope to also shape what happens after. 


\section{REFERENCES}

Ai, C., and E. C. Norton

2003 "Interaction terms in logit and probit models." Economic Letters, 80:123-9.

Altonji, J. G., and R. M. Blank

1999 "Race and gender in the labor market." In O. Ashenfelter, and D. Card (eds.), Handbook of Labor Economics, 3: 3143-259. Amsterdam, Netherlands: Elsevier Science.

Anderson, M., A. W. Astin, D. A. Bell, Jr., J. B. Cole, A. Etzioni, W. Gellhorn, P. A. Griffiths, A. Hacker, T. M.Hesburgh, W. E. Massey, and R. Wilson

1993 "Why the shortage of black professors?" The Journal of Blacks in Higher Education, 1: $25-34$.

Attiyeh, G., and R. Attiyeh

1997 "Testing for bias in graduate school admissions." The Journal of Human Resources, 32: 524-548.

Barbezat, D. A.

1991 "Updating estimates of male-female salary differentials in the academic labor market." Economics Letters, 36: 191-195.

Becker, G. S.

1971 The Economics of Discrimination. Chicago, IL: University of Chicago Press.

Becher, T.

1994 "The significance of disciplinary differences." Studies in Higher Education, 19: 151-161.

Bertrand, M., and S. Mullainathan

2004 "Are Emily And Greg more employable than Lakisha and Jamal? A field experiment on labor market discrimination." American Economic Review, 94: 991-1013.

Bertrand, M., D. Chugh, and S. Mullainathan

2005 "Implicit discrimination." American Economic Review, 95: 94-98.

Bertrand, M., C. Goldin, and L. F. Katz

2010 "Dynamics of the gender gap for young professionals in the financial and corporate sectors.” American Economic Journal: Applied Economics, 2: 228-255.

Bettinger, E. P., and B. T. Long

2005 "Do faculty serve as role models? The impact of instructor gender on female students."

The American Economic Review, 95: 152-157.

Brigham, J. C. 
1993 "College students' racial attitudes." Journal of Applied Social Psychology, 23: 19331967.

Byrne, D.

1971 The attraction paradigm. New York, NY: Academic Press.

Byrne, R.

2008 "Gap persists between faculty salaries at public and private institutions." Chronicle of Higher Education, 54.

Carpenter, J. P., G. W. Harrison, and J. A. List

2004 "Field experiments in economics: An introduction." Research in Experimental Economics, 10: 1-16.

Carr, P. L., A. S. Ash, R. H. Friedman, L. Szalacha, R. C. Barnett, A. Palepu, and M. M. Moskowitz

2000 "Faculty perceptions of gender discrimination and sexual harassment in academic medicine." Annals of Internal Medicine, 132: 889-896.

Caruso, E. M., K. D. Vohs, B. Baxter, and A. Waytz

2012 "Mere exposure to money Increases endorsement of free market systems and social inequality." Journal of Experimental Psychology: General, 142: 301-306.

Castilla, E. J., and S. Benard

2010 "The paradox of meritocracy in organizations." Administrative Science Quarterly, 55: 543-676.

Ceci, S. J., and W. M. Williams

2011 "Understanding current causes of women's underrepresentation in science." Proceedings of the National Academy of Sciences, 108: 3157-62.

Ceci, S. J., W. M. Williams, R. A. Sumner, and W. C. DeFraine

2011 "Do subtle cues about belongingness constrain women's career choices?" Psychological Inquiry, 22: 255-258.

Chugh, D., and A. Brief

2008 "1964 was not that long ago: A story of gateways and pathways." In A. P. Brief (ed.), Diversity at Work, 318-340. Cambridge, England: Cambridge University Press.

Clark, S. M., and M. Corcoran

1986 "Perspectives on the professional socialization of women faculty: A case of accumulative disadvantage?" The Journal of Higher Education, 57: 20-43.

Cochran, W. G.

1963 Sampling Techniques. New York, NY: Wiley. 
Cole, J.

1979 Fair Science: Women in the Scientific Community. New York, NY: Columbia University Press.

Correll, S. J.

2001 "Gender and the career choice process: The role of biased self-assessments." American Journal of Sociology, 106: 1691-1730.

Correll, S. J.

2004 "Constraints into preferences: Gender, status, and emerging career aspirations." American Sociological Review, 69: 93-113.

Correll, S. J., S. Benard, and I. Paik

2007 "Getting a job: Is there a motherhood penalty?" American Journal of Sociology, 112: $1297-1339$.

Cota, A. A., and K. L. Dion

1986 "Salience of gender and sex composition of ad hoc groups: An experimental test of distinctiveness theory." Journal of Personality and Social Psychology, 50: 770-776.

Crenshaw, K.

1991 "Mapping the margins: Intersectionality, identity politics, and violence against women of color.” Stanford Law Review, 43: 1241-1299.

Croson, R., and U. Gneezy

2009 "Gender differences in preferences." Journal of Economic Literature, 47: 448-474.

DiPrete, T. A., and G. M. Eirich

2006 "Cumulative advantage as a mechanism for inequality: A review of theoretical and empirical developments.” Annual Review of Sociology, 32: 271-297.

Dovidio, J. F., and S. L. Gaertner

1998 "On the nature of contemporary prejudice: The causes, consequences, and challenges of aversive racism.” In J. L. Eberhart and S. T. Fiske (eds.), Confronting Racism: The Problem and the Response, 234-262. Thousand Oaks, CA: Sage Publications.

Ely, R. J.

1995 "The power in demography: Women's social constructions of gender identity at work." Academy of Management Journal, 38: 589-634.

Erickson, H. P.

2011 "Race disparity in grants: Check the citations." Science 334: 899-901.

Feagin, J. R., and M. P. Sikes

1995 "How black students cope with racism on white campuses." The Journal of Blacks in Higher Education, 8: 91-97. 
Fernandez, R. M., and J. Greenberg

2013 "Race, network hiring, and statistical discrimination." In S. McDonald (ed.), Research in the Sociology of Work, 24: 81-102, United Kingdom: Emerald Group Publishing.

Fix, M., and R. J. Struyk

1992 Clear and Convincing Evidence: Measurement of Discrimination in America. Lanham, MD: Urban Institute Press.

Frable, D. E.

1997 "Gender, racial, ethnic, sexual, and class identities." Annual Review of Psychology, 48: $139-162$.

Gersick, C. J. G., J. E. Dutton, and J. M. Bartunek

2000 "Learning from academia: The importance of relationship in professional life." Academy of Management Journal, 43: 1026-1044.

Ginther, D. K.

2006 "The economics of gender differences in employment outcomes in academia." Biological, Social, and Organizational Components of Success for Women in Science and Engineering: Workshop Report. Washington, DC: National Academies Press.

Ginther, D. K., W. T. Schaffer, J. Schnell, B. Masimore, F. Liu, L. L. Haak, and R. Kington 2011 "Race, ethnicity, and NIH research awards." Science 333: 1015-1019.

Greenwald, A. G., and M. R. Banaji

1995 "Implicit social cognition: Attitudes, self-esteem, and stereotypes." Psychological Review, 102: 4-27.

Griffith, A. L.

2010 "Persistence of women and minorities in STEM field majors: Is it the school that matters?" Economics of Education Review, 29: 911-922.

Handelsman, J., N. Cantor, M. Carnes, D. Denton, E. Fine, B. Grosz, V. Hinshaw, C. Marrett, S. Rosser, D. Shalala, and J. Sheridan

2005 "More women in science." Science, 5738: 1190-1191.

Heckman, J. J.

1998 "Detecting discrimination." The Journal of Economic Perspectives, 12: 101-116.

Hogg, M. A., and D. I. Terry

2000 "Social identity and self-categorization processes in organizational contexts." Academy of management review, 25: 121-140.

Hoxby, C. M., and C. Avery 
2012 "The missing "one-offs": The hidden supply of high-achieving, low income students." National Bureau of Economic Research Working Paper No. 18586.

Ibarra, $\mathrm{H}$.

1992 "Homophily and differential returns: Sex differences in network structure and access in an advertising firm." Administrative Science Quarterly, 422-447.

Johnsrud, L. K., and K. C. Sadao

1998 "The common experience of "otherness": Ethnic and racial minority faculty." The Review of Higher Education, 21: 315-342.

Kalev, A., F. Dobbin, and E. Kelly

2006 "Best practices of best guesses? Assessing the efficacy of corporate affirmative action and diversity policies." American Sociological Review, 71: 589-617.

Khurana, R.

2007 From Higher Aims to Hired Hands: The Social Transformation of American Business Schools and the Unfulfilled Promise of Management as a Profession. Princeton: Princeton University Press.

Kolpin, V. W., and L. D. Singell, Jr.

1996 "The gender composition and scholarly performance of economics departments: A test for employment discrimination." Industrial and Labor Relations Review, 49: 408-423.

Kraus, M. W., and D. Keltner

2009 "Signs of socioeconomic status: A thin-slicing approach." Psychological Science, 20: 99106.

Kraus, M. W., S. Côté, and D. Keltner

2010 "Social class, contextualism, and empathic accuracy." Psychological Science, 21: 17161723.

Lauderdale, D.S., and B. Kestenbaum

2000 "Asian American ethnic identification by surname." Population Research and Policy Review, 19: 283-300.

Lawrence, B. S., and P. S. Tolbert

2007 "Organizational demography and individual careers: Structure, norms, and outcomes." In H. Gunz \& M. Peiperl (eds.), Handbook of Career Studies, 399-421. Thousand Oaks, CA: SAGE.

Lincoln, J. R., and J. Miller

1979 "Work and friendship ties in organizations: A comparative analysis of relation networks." Administrative Science Quarterly, 24: 181-199.

Long J. S., P. D. Allison, and R. McGinnis 
1993 "Rank advancement in academic careers: Sex differences and the effects of productivity." American Sociological Review, 58: 703-722.

Long, J. S., and M. F. Fox

1995 "Scientific careers: Universalism and particularism." Annual Review of Sociology, 21: $45-71$.

Massey, D. S.

2007 Categorically Unequal: The American Stratification System. New York, NY: Russell Sage Foundation.

McCall, L.

2005 "The complexity of intersectionality." Signs, 30: 123-144.

McPherson, M., L. Smith-Lovin, and J. M. Cook

2001 "Birds of a feather: Homophily in social networks." Annual Review of Sociology, 27: 415-444.

Menges, R. J., and W. H. Exum

1983 "Barriers to the progress of women and minority faculty." The Journal of Higher Education, 54: 123-144.

Merton, R. K.

1973 "The Matthew effect in science." Science, 159: 56-63.

McGinn, K.L., and K.L. Milkman

2013 "Looking up and looking out: Career mobility effects of demographic similarity among professionals.” Organization Science, 24: 1041-1060.

Milkman, K. L., M. Akinola, and D. Chugh

2012 "Temporal distance and discrimination: An audit study in academia." Psychological Science, 23: 710-717.

Moss-Racusin, C. A., J. F. Dovidio, V. L. Brescoll, M. J. Graham, and J. Handelsman 2012 "Science faculty's subtle gender biases favor male students." Proceedings of the National Academic of Sciences of the United States of America, 109: 16474-16479.

Myers, S. L., and C. S. Turner

2004 "The effects of Ph. D. supply on minority faculty representation." American Economic Review, 94: 296-301.

Nakhaie, M. R.

2007 "Universalism, ascription and academic rank: Canadian professors, 1987-2000."

Canadian Review of Sociology/Revue Canadienne de Sociologie, 44: 361-386.

National Science Foundation 
2009 "Women, minorities, and persons with disabilities in science and engineering." http://www.nsf.gov/statistics/women/.

National Science Foundation

2012 "Survey of earned doctorates. Doctorate recipients from U.S. universities: 2012." http://www.nsf.gov/statistics/srvydoctorates/.

National Center for Educational Statistics

2012 "National study of postsecondary faculty." http://nces.ed.gov/surveys/nsopf/.

Neckerman, K. M.., and J. Kirschenman

1991 "Hiring strategies, racial bias and inner city workers." Social Problems, 38: 433-447.

Neumark, D., R. J. Bank, and K. D. Van Nort

1996 "Sex discrimination in restaurant hiring: An audit study." The Quarterly Journal of Economics, 111: 915-941.

Nosek, B. A., M. Banaji, and A. G. Greenwald

2002 "Harvesting implicit group attitudes and beliefs from a demonstration web site." Group

Dynamics: Theory, Research, and Practice, 6: 101-115.

Pager, D.

2007 "The use of field experiments for studies of employment discrimination: Contributions, critiques, and directions for the future." The Annals of the American Academy of Political and Social Science, 609: 104-133.

Pager, D., and H. Shepherd

2008 "The sociology of discrimination: Racial discrimination in employment, housing, credit, and consumer markets." Annual Review of Sociology, 34: 181-209.

Pager, D., and L. Quillian

2005 "Walking the talk? What employers say versus what they do." American Sociological Review, 70: 355-380.

Pager, D., B. Western and B. Bonikowski

2009 "Discrimination in a low-wage labor market: A field experiment." American Sociological Review, 74: 777-799.

Perna, L. W.

2001 "Sex and race differences in faculty tenure and promotion." Research in Higher Education, 42: 541-567.

Petersen, T., I. Saporta, and M. L. Seidel

2000 "Offering a job: Meritocracy and social networks." American Journal of Sociology, 106: 763-816. 
Phelps, E. S.

1972 "The statistical theory of racism and sexism." The American Economic Review, 62: 659661.

Piff, P. K., M. W. Kraus, S. Côté, B. H. Cheng, and D Keltner

2010 "Having less, giving more: The influence of social class on prosocial behavior." Journal of Personality and Social Psychology, 99: 771-784.

Piff, P. K., D. M. Stancato, S. Côté, R. Mendoza-Denton, and D. Keltner

2012 "Higher social class predicts increased unethical behavior." Proceedings of the National Academy of Sciences, 109: 4086-4091.

Porter, J. R., and R. E. Washington

1993 "Minority identity and self-esteem." Annual Review of Sociology, 19: 139-161.

Pratto, F., J. Sidanius, L. M. Stallworth, and B. F. Malle

1994 "Social dominance orientation: A personality variable predicting social and political attitudes." Journal of Personality and Social Psychology, 67: 741-763.

Price, J. and J. Wolfers

2010 "Racial discrimination among NBA referees." Quarterly Journal of Economics, 125: $1859-1887$.

Quillian, L.

2006 "New approaches to understanding racial prejudice and discrimination." Annual Review of Sociology, 32: 299-328.

Ransom, M. R., and S. B. Megdal

1993 "Sex differences in the academic labor market in the affirmative action era." Economics of Education Review, 12: 21-43.

Rask, K. N., and E. M. Bailey

2002 "Are faculty role models? Evidence from major choice in an undergraduate Institution." The Journal of Economic Education, 33: 99-124.

Ridgeway, C. L.

2009 "Framed before we know it: How gender shapes social relations." Gender \& Society, 23: $145-160$.

Ross, L., and R. E. Nisbett

1991 The Person and the Situation: Perspectives of Social Psychology. New York, NY: Mcgraw-Hill Book Company.

Rosser, S. V., and E. O. Lane 
2002 "Key barriers for academic institutions seeking to retain female scientists and engineers: Family-unfriendly policies, low numbers, stereotypes and harassment." Journal of Women and Minorities in Science and Engineering, 8: 163-191.

Rowe, M.

1981 "The minutiae of discrimination: The need for support." In B. Forisha and B. Goldman (eds.), Outsiders on the Inside, Women in Organizations, NJ: Prentice Hall, Inc.

Rowe, M.

2008 "Micro-affirmations and micro-inequalities." Journal of the International Ombudsman Association, 1: 1-9.

Rubineau, B., and Y Kang

2012 "Bias in white: A longitudinal natural experiment measuring changes in discrimination." Management Science, 58: 660-677.

Seymour, E., and N. M. Hewitt

1997 Talking About Leaving: Why Undergraduates Leave the Sciences. Boulder, CO:

Westview Press.

Smith, R. A.

2002 "Race, gender, and authority in the workplace: Theory and research." Annual Review of Sociology, 28: 509-542.

Sonnert, G.

1990 "Careers of women and men postdoctoral fellows in the sciences." Paper presented at the Annual Meeting of the American Sociological Association, Washington, DC.

Sonnert, G., and M. F. Fox

2012 "Women, men, and academic performance in science and engineering: The gender difference in undergraduate grade point averages." The Journal of Higher Education, 83: $73-$ 101.

Sonnert, G., and G. Holton

1996 "Career patterns of women and men in the sciences." American Scientist, 84: 63-71.

Sonnert, G., M. F. Fox, and K. Adkins

2007 "Undergraduate women in science and engineering: Effects of faculty, fields, and institutions over time.” Social Science Quarterly, 88: 1333-1356.

Steinpreis, R. E., K. A. Anders, and D. Ritzke

1999 "The Impact of gender on the review of the curricula vitae of job applicants and tenure candidates: A national empirical study." Sex Roles, 41: 509-528.

Stockdill, B. C., and M. Y. Danico 
2012 Transforming the Ivory Tower: Challenging Racism, Sexism, and Homophobia in the Academy. Honolulu, HI: University of Hawaii Press.

Sue, D. W.

2010 Microaggressions in everyday life: Race, gender, and sexual orientation. Hoboken, NJ: Wiley.

Tajfel, H., and J. C. Turner

1986 "The social identity theory of intergroup behaviour." In S. Worchel and W. G. Austin (eds.), Psychology of Intergroup Relations, 7-24. Chicago, IL: Nelson-Hall.

Tolbert, P. S., T. Simons, A. Andrews, and J. Thee

1995 "The effects of gender composition in academic departments on faculty turnover." Industrial and Labor Relations Review, 48: 562-579.

Tolbert, P., and A. Oberfield

1991 Sources of organizational demography: Faculty sex ratios in colleges and universities. Sociology of Education, 64: 305-315.

Toutkoushian, R. K.

1998 "Racial and marital status differences in faculty pay." The Journal of Higher Education, 69: 513-541.

Trower, C. A., and R. P. Chait

2002 "Faculty diversity: Too little for too long." Harvard Magazine, Mar-Apr 23-28.

Turner, C., S. L. Myers, Jr., and J. W. Creswell

1999 "Exploring underrepresentation: The case of faculty of color in the midwest." The Journal of Higher Education, 70: 27-59.

Turner, M. A., and S. L. Ross

2003 Discrimination in Metropolitan Housing Markets: Phase 2-Asians and Pacific Islanders of the HDS 2000. Washington, DC: U.S. Department of Housing and Urban Development.

Turner, M. A., S. L. Ross, G. Galster, and J. Yinger

2002 Discrimination in Metropolitan Housing Markets: Phase I-National Results from Phase I of the HDS 2000. Washington, DC: U.S. Department of Housing and Urban Development.

U.S. Department of Education, National Center for Education Statistics

2009 "2008-09 integrated postsecondary education data system."

http://nces.ed.gov/IPEDS/news_room/ana_Changes_to_8_22_2008_188.asp.

U.S. Department of Education, National Center for Education Statistics 
2010 "2005, 2007, and 2009 integrated postsecondary education data system (IPEDS), winter 2005-06, winter 2007-08, and winter 2009-10.”

http://nces.ed.gov/programs/digest/d10/tables/dt10_260.asp.

U.S. News and World Report

2010 "Best colleges 2010: National universities."

http://colleges.usnews.rankingsandreviews.com/best-colleges/national-universities-rankings).

Valian, V.

1999 Why So Slow?: The Advancement of Women. Cambridge, MA: The MIT Press.

Winship, C., and L. Radbill

1994 "Sampling weights and regression analysis." Sociological Methods and Research, 23: 230-257.

Word, D. L., and R. C. Perkins, Jr.

1996 Building a Spanish Surname List for the 1990s-A New Approach to an Old Problem. Technical Working Paper No. 13. Population Division, U.S. Bureau of the Census. 


\section{FIGURES}

Figure 1. Figures $\mathrm{a}$ and $\mathrm{b}$ show the regression-estimated size of the discriminatory gap faced by women and minorities by broad discipline. Narrower disciplinary categories are also analyzed later in our paper.

Figure 1a. Discriminatory Gap: Caucasian Males vs. Other Students ${ }^{\mathrm{a}}$

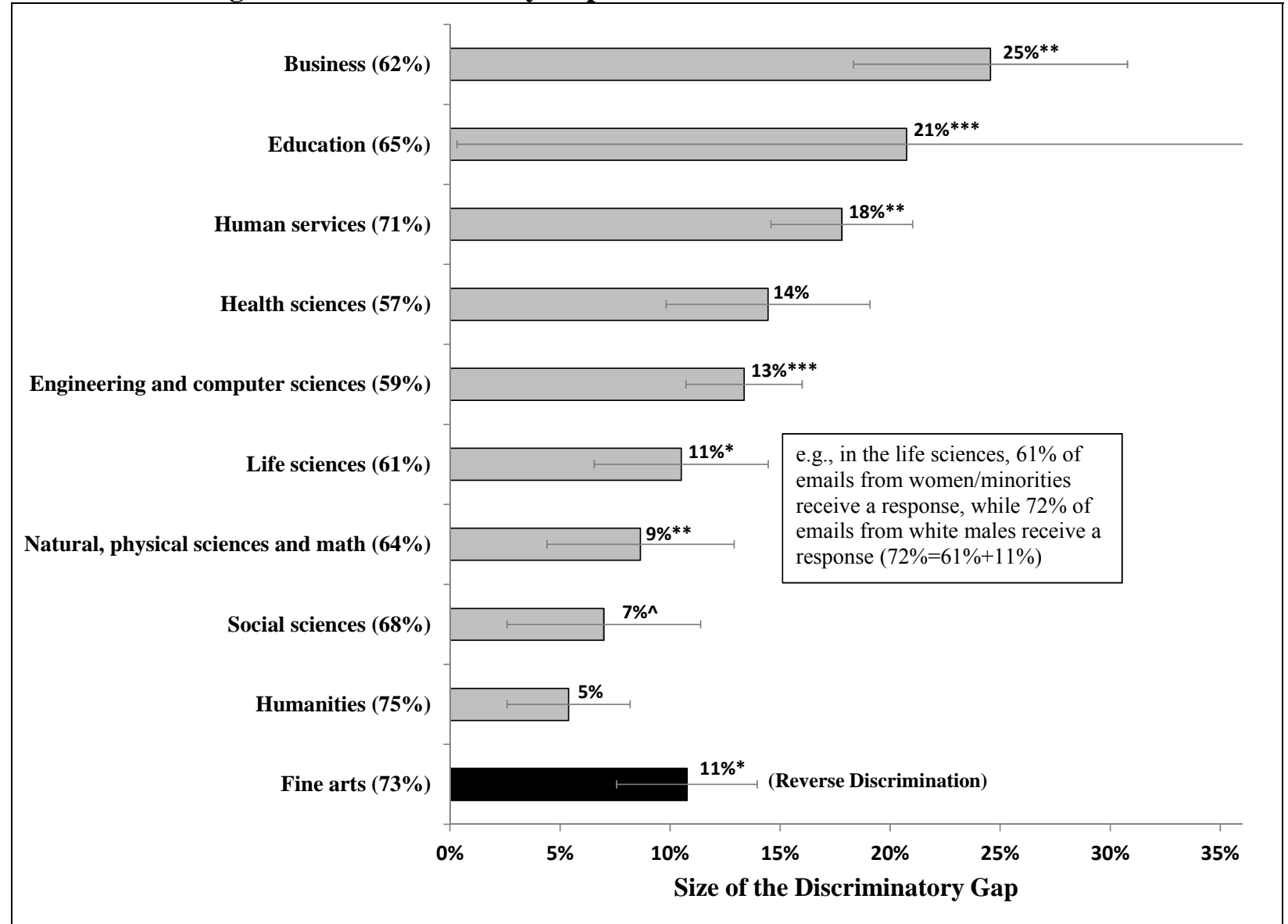

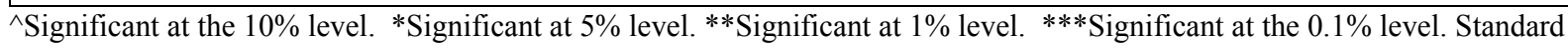
error bars depicted.

${ }^{a}$ Response rate to minorities/females in parentheses after the discipline's name. See Table 2 for similar, raw summary statistics. 
Figure 1b. Discriminatory Gap: Caucasian Males vs. Students of Each Race/Gender Combination

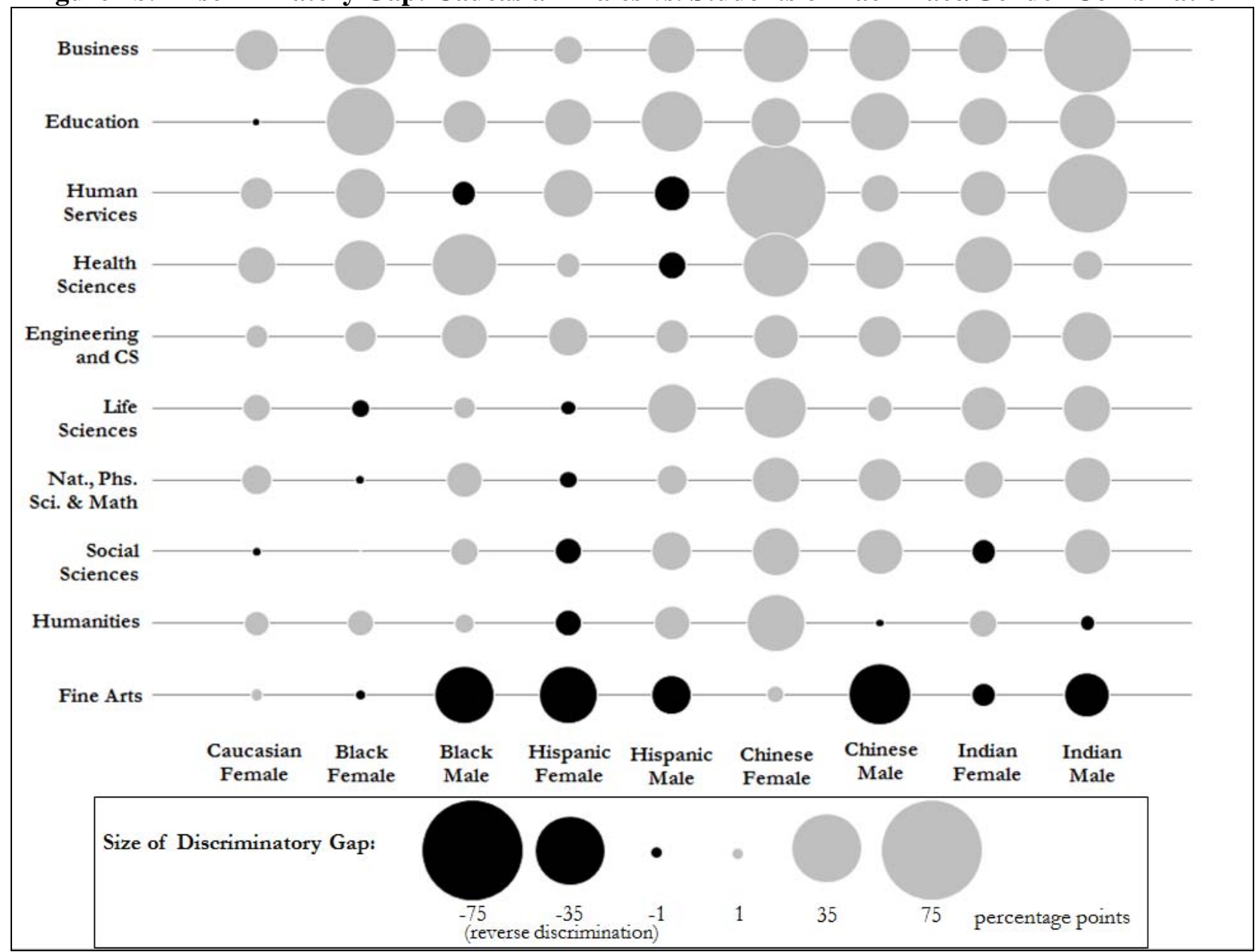

Note: Reverse-discrimination in black. Disciplines are sorted by the size of the discriminatory gap. The discipline-by-discipline estimates of bias presented here rely on an ordinary least squares (OLS) linear regression to predict whether a given faculty member responds to a given student's email as a function of the faculty member's broad discipline and an interaction between discipline and whether the student is a minority or female, controlling for all observable characteristics of the email and its recipient (and suppressing the regression's constant so estimates can be obtained for each discipline). Of the 6,548 faculty in our study, 28 could not be classified into academic disciplines recognized by the NSOFP, and one worked in a vocational discipline; these 29 are thus dropped from our discipline-by-discipline analyses. See Appendix for similar, raw summary statistics. 
Figure 2. Sample-weighted discriminatory gap experienced by minority and female students relative to Caucasian males as a function of the avg. 9-mo. salary in a faculty member's narrow NSOPF discipline.

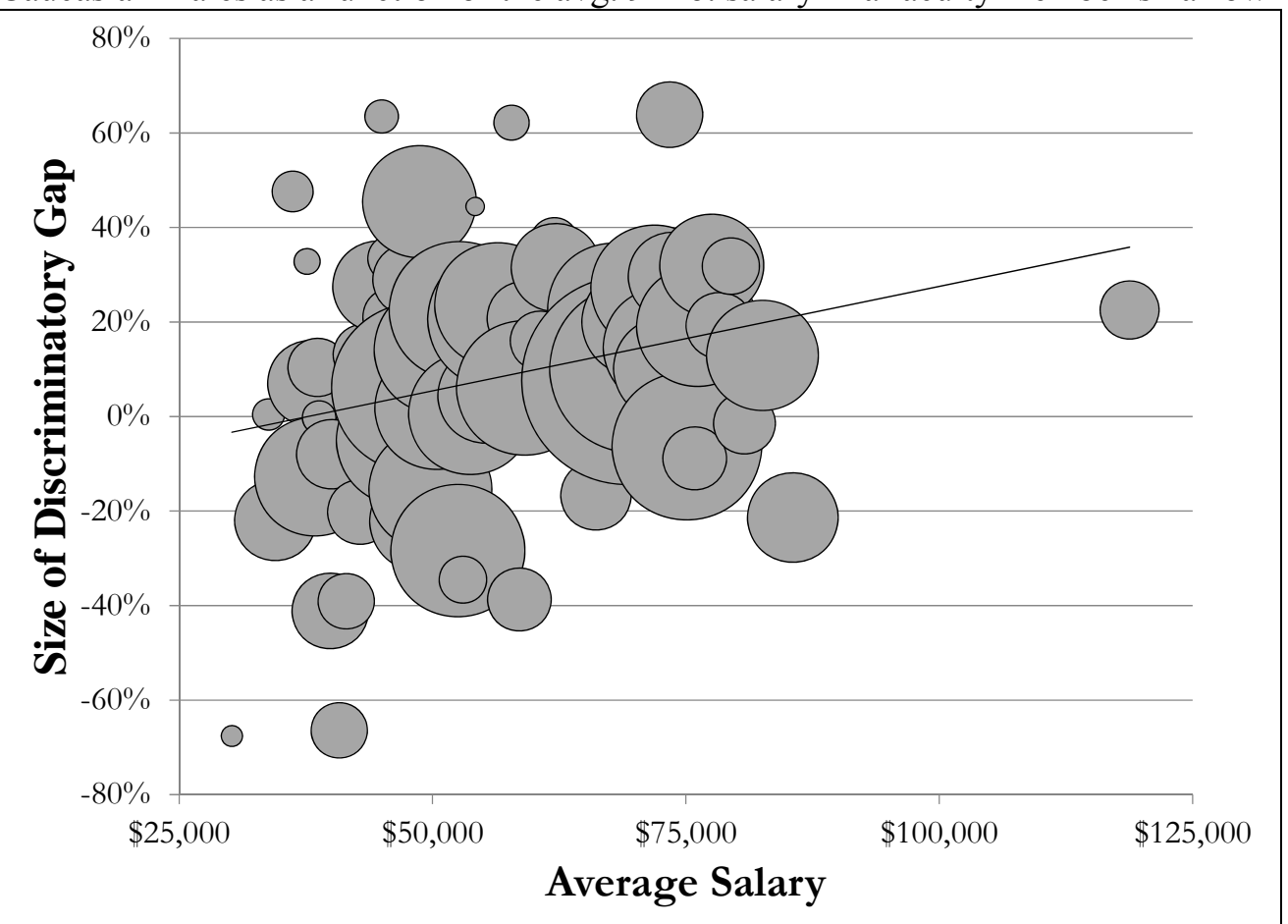

Note. Each bubble represents one discipline and bubble sizes are proportional to the study's sample size in a given discipline. Negative numbers indicate reverse discrimination. 
Figure 3. Regression-estimated size of the discriminatory gap faced by female and minority students at public versus private universities.

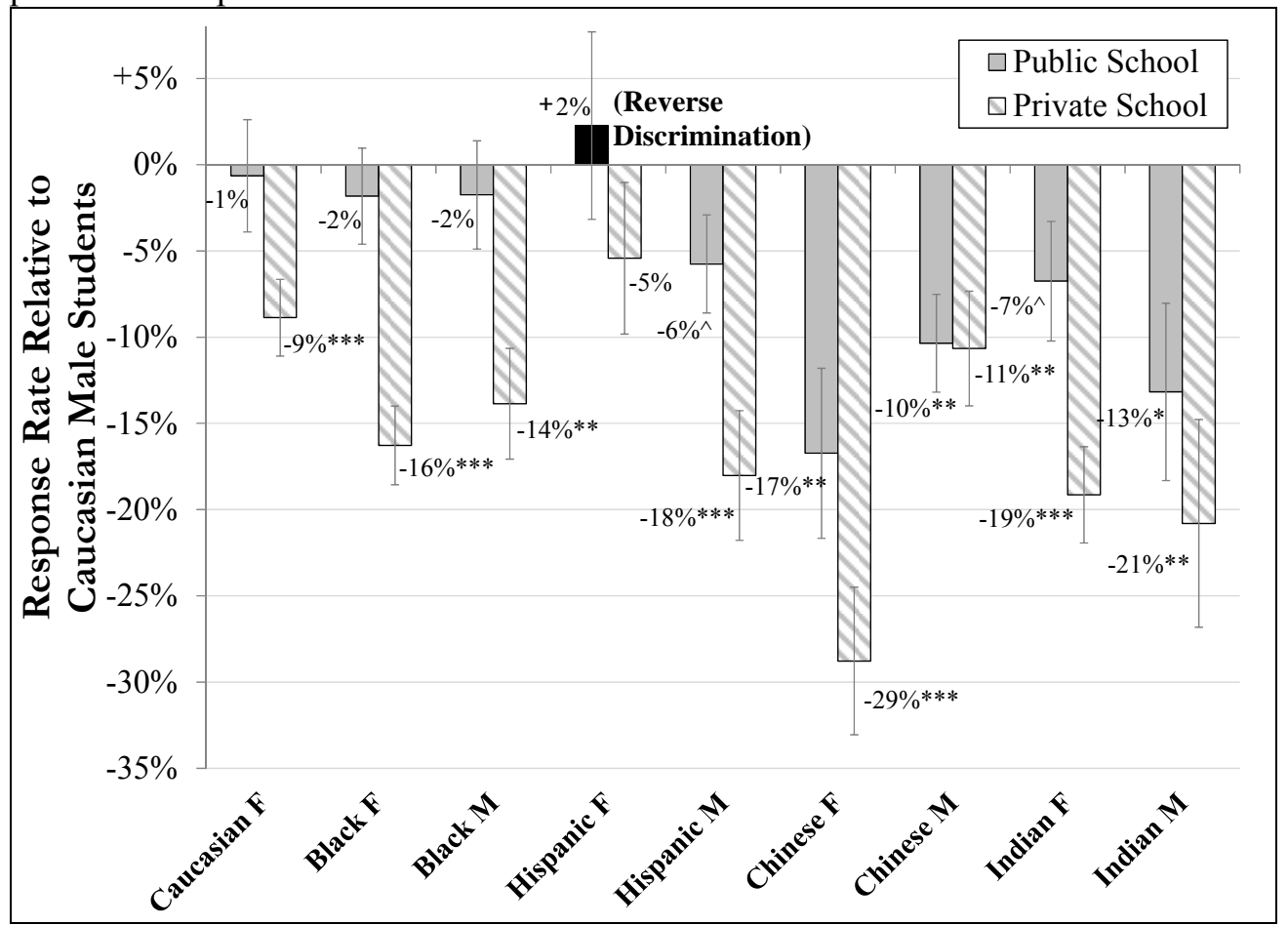

Note. Reverse-discrimination in black. See Appendix for similar raw summary statistics. ${ }^{\wedge}$ Significant at the $10 \%$ level. *Significant at $5 \%$ level. **Significant at $1 \%$ level. ${ }^{* * *}$ Significant at the $0.1 \%$ level. Standard error bars depicted. 
Table 1. Race and Gender Recognition Survey Results for Selected Names

\begin{tabular}{|c|c|c|c|c|}
\hline Race & Gender & Name & Rate of Race Recognition & Rate of Gender Recognition \\
\hline \multirow{4}{*}{ Caucasian } & \multirow{2}{*}{ Male } & Brad Anderson & $100 \%{ }^{* * *}$ & $100 \%{ }^{* * *}$ \\
\hline & & Steven Smith & $100 \%{ }^{* * *}$ & $100 \%^{* * *}$ \\
\hline & \multirow{2}{*}{ Female } & Meredith Roberts & $100 \%^{* * *}$ & $100 \%^{* * *}$ \\
\hline & & Claire Smith & $100 \%{ }^{* * *}$ & $100 \%{ }^{* * *}$ \\
\hline \multirow{4}{*}{ Black } & \multirow{2}{*}{ Male } & Lamar Washington & $100 \%{ }^{* * *}$ & $100 \%^{* * *}$ \\
\hline & & Terell Jones & $100 \%^{* * *}$ & $94 \%^{* * *}$ \\
\hline & \multirow{2}{*}{ Female } & Keisha Thomas & $100 \%{ }^{* * *}$ & $100 \%{ }^{* * *}$ \\
\hline & & Latoya Brown & $100 \%{ }^{* * *}$ & $100 \%{ }^{* * *}$ \\
\hline \multirow{4}{*}{ Hispanic } & \multirow{2}{*}{ Male } & Carlos Lopez & $100 \%{ }^{* * *}$ & $100 \%{ }^{* * *}$ \\
\hline & & Juan Gonzalez & $100 \%{ }^{* * *}$ & $100 \%{ }^{* * *}$ \\
\hline & \multirow{2}{*}{ Female } & Gabriella Rodriguez & $100 \%{ }^{* * *}$ & $100 \%{ }^{* * *}$ \\
\hline & & Juanita Martinez & $100 \%{ }^{* * *}$ & $100 \%{ }^{* * *}$ \\
\hline \multirow{4}{*}{ Indian } & \multirow{2}{*}{ Male } & Raj Singh & $90 \%{ }^{* * * *}(10 \%$ Other $)$ & $100 \%{ }^{* * *}$ \\
\hline & & Deepak Patel & $85 \%^{* * *}(15 \%$ Other $)$ & $100 \%^{* * *}$ \\
\hline & \multirow{2}{*}{ Female } & Sonali Desai & $85 \%{ }^{* * *}(15 \%$ Other $)$ & $100 \%^{* * *}$ \\
\hline & & Indira Shah & $85 \%{ }^{* * *}(10 \%$ Other; $5 \%$ Hispanic $)$ & $94 \%{ }^{* * *}$ \\
\hline \multirow{4}{*}{ Chinese } & \multirow{2}{*}{ Male } & Chang Huang & $100 \%{ }^{* * *}$ & $94 \%{ }^{* * *}$ \\
\hline & & Dong Lin & $100 \%^{* * *}$ & $94 \%^{* * *}$ \\
\hline & \multirow{2}{*}{ Female } & Mei Chen & $100 \%{ }^{* * *}$ & $94 \%{ }^{* * *}$ \\
\hline & & Ling Wong & $100 \%{ }^{* * *}$ & $78 \%{ }^{*}$ \\
\hline
\end{tabular}

Note. We conducted a survey to test how effectively a set of 90 names signaled different races and genders. Thirty-eight participants who had signed up to complete online paid polls through Qualtrics and who had received a Master's degree (87.5\%) or $\mathrm{PhD}(12.5 \%)$ were recruited to participate in a survey online. Their task was to predict the race or gender associated with a given name for a set of 90 names. We selected the two names of each race and gender from these surveys with the highest net recognition rates on race (avg. $=97 \%$ ) and gender (avg.=98\%) to use in our study. For additional discussion of this selection procedure, see our Appendix. This table also appears in (Milkman, Akinola and Chugh, 2012). Reported significance levels indicate the results of a two-tailed, one sample test of proportions to test the null hypothesis that the observed recognition rate is equal to that expected by chance $(16.7 \%$ for race and $50 \%$ for gender). $* * * p<0.001 ; * * p<0.01 ; * p<0.05$ 
Table 2. Descriptive Statistics for Faculty Included in Study by Broad Discipline and University Type (Public vs. Private)

\begin{tabular}{|c|c|c|c|c|c|c|c|c|c|c|c|c|}
\hline & & & & & & \multicolumn{7}{|c|}{ Sample-Weighted Representation } \\
\hline & $\mathbf{N}$ & $\begin{array}{c}\text { Avg. Size of } \\
\text { Discriminatory } \\
\text { Gap }\end{array}$ & $\begin{array}{c}\text { \# of Narrow } \\
\text { Sub- } \\
\text { Disciplines* }\end{array}$ & & $\begin{array}{l}\text { vg. Base } \\
\text { Month) } \\
\text { Salary }\end{array}$ & Female & Caucasian & Black & Hispanic & Chinese & Indian & $\begin{array}{c}\text { Other } \\
\text { Race }\end{array}$ \\
\hline \multicolumn{13}{|l|}{ Broad Discipline } \\
\hline Business & 265 & $19 \%$ & 7 & $\$$ & 63,651 & $26 \%$ & $85 \%$ & $2 \%$ & $1 \%$ & $4 \%$ & $5 \%$ & $4 \%$ \\
\hline Education & 441 & $17 \%$ & 16 & $\$$ & 45,897 & $55 \%$ & $91 \%$ & $2 \%$ & $2 \%$ & $2 \%$ & $1 \%$ & $3 \%$ \\
\hline Engineering \& Computer Science & 1,125 & $9 \%$ & 14 & $\$$ & 71,107 & $15 \%$ & $78 \%$ & $1 \%$ & $1 \%$ & $8 \%$ & $8 \%$ & $4 \%$ \\
\hline Fine Arts & 209 & $-17 \%$ & 8 & $\$$ & 38,023 & $38 \%$ & $92 \%$ & $1 \%$ & $1 \%$ & $4 \%$ & $1 \%$ & $2 \%$ \\
\hline Health Sciences & 343 & $11 \%$ & 12 & $\$$ & 69,222 & $46 \%$ & $91 \%$ & $2 \%$ & $0 \%$ & $3 \%$ & $1 \%$ & $2 \%$ \\
\hline Human Services & 188 & $14 \%$ & 10 & $\$$ & 49,257 & $43 \%$ & $87 \%$ & $4 \%$ & $2 \%$ & $1 \%$ & $1 \%$ & $5 \%$ \\
\hline Humanities & 668 & $1 \%$ & 5 & $\$$ & 46,375 & $38 \%$ & $90 \%$ & $2 \%$ & $2 \%$ & $2 \%$ & $2 \%$ & $2 \%$ \\
\hline Life Sciences & 1,051 & $6 \%$ & 9 & $\$$ & 70,123 & $24 \%$ & $90 \%$ & $0 \%$ & $1 \%$ & $4 \%$ & $3 \%$ & $2 \%$ \\
\hline Natural, Physical Sciences \& Math & 850 & $6 \%$ & 9 & $\$$ & 60,245 & $18 \%$ & $85 \%$ & $1 \%$ & $1 \%$ & $7 \%$ & $4 \%$ & $3 \%$ \\
\hline Social Sciences & 1,379 & $2 \%$ & 19 & $\$$ & 52,889 & $38 \%$ & $90 \%$ & $2 \%$ & $2 \%$ & $2 \%$ & $2 \%$ & $3 \%$ \\
\hline \multicolumn{13}{|l|}{ University Type } \\
\hline Public & 4,450 & $2 \%$ & 105 & & $\$ X$ & $30 \%$ & $87 \%$ & $1 \%$ & $2 \%$ & $5 \%$ & $4 \%$ & $2 \%$ \\
\hline Private & 2,098 & $12 \%$ & 100 & & $+\$ 34,687$ & $32 \%$ & $88 \%$ & $1 \%$ & $1 \%$ & $4 \%$ & $2 \%$ & $3 \%$ \\
\hline
\end{tabular}

Note. The 9-month salaries reported here are lower than those paid at many top institutions but reflect the average salaries across disciplines sampled by the NSOPF, which "includes a nationally representative sample of...faculty.... at public and private notfor-profit two- and four-year institutions in the United States" (http://www.icpsr.umich.edu/icpsrweb/ICPSR/series/194). 
Table 3. Estimated effects of students' race and gender, the (standardized) demographic composition of a professor's academic discipline and university, and the interaction between minority student status and these discipline and university demographics on whether professors respond to emails. Standard errors are clustered by university and academic discipline. The Appendix offers definitions for the primary predictor variables in this table.

\begin{tabular}{|c|c|c|c|c|c|c|c|c|}
\hline & \multicolumn{2}{|c|}{ Model 1} & \multicolumn{2}{|c|}{ Model 2} & \multicolumn{2}{|c|}{ Model 3} & \multicolumn{2}{|c|}{ Model 4} \\
\hline & $\beta$ & Std. Err. & $\beta$ & Std. Err. & $\beta$ & Std. Err. & $\beta$ & Std. Err. \\
\hline \multicolumn{9}{|l|}{ Academic Discipline Characteristics } \\
\hline Faculty \% Black & 0.004 & $(0.006)$ & & & 0.006 & $(0.006)$ & & \\
\hline (Fac\%Black) x (Black Student) & 0.000 & $(0.014)$ & & & -0.002 & $(0.015)$ & & \\
\hline Faculty \% Hispanic & 0.010 & $(0.007)$ & & & $0.012^{\wedge}$ & $(0.006)$ & & \\
\hline (Fac\%Hispanic) x (Hispanic Student) & -0.001 & $(0.010)$ & & & -0.003 & $(0.012)$ & & \\
\hline Faculty \% Asian & -0.011 & $(0.012)$ & & & -0.013 & $(0.013)$ & & \\
\hline (Fac\%Asian) x (Asian Student) & 0.000 & $(0.014)$ & & & 0.005 & $(0.015)$ & & \\
\hline Faculty \% Minority & & & 0.000 & $(0.011)$ & & & 0.001 & $(0.011)$ \\
\hline (Fac\%Minority) x (Minority Student) & & & -0.007 & $(0.014)$ & & & -0.005 & $(0.015)$ \\
\hline Faculty \% Female & $0.018^{\wedge}$ & $(0.010)$ & $0.031^{* * *}$ & $(0.010)$ & $0.019^{\wedge}$ & $(0.011)$ & $0.033^{* *}$ & $(0.011)$ \\
\hline (Fac\%Female) x (Female Student) & -0.007 & $(0.014)$ & -0.006 & $(0.014)$ & -0.009 & $(0.015)$ & -0.008 & $(0.015)$ \\
\hline PhD Students \% Black & 0.000 & $(0.010)$ & & & -0.005 & $(0.010)$ & & \\
\hline (PhD\%Black) x (Black Student) & -0.018 & $(0.014)$ & & & -0.014 & $(0.015)$ & & \\
\hline PhD Students \% Hispanic & 0.007 & $(0.009)$ & & & 0.010 & $(0.008)$ & & \\
\hline (PhD\%Hispanic) x (Hispanic Student) & 0.010 & $(0.014)$ & & & 0.003 & $(0.013)$ & & \\
\hline PhD Students \% Asian & -0.003 & $(0.011)$ & & & -0.003 & $(0.012)$ & & \\
\hline (PhD\%Asian) x (Asian Student) & $-0.022^{\wedge}$ & $(0.013)$ & & & $-0.026^{\wedge}$ & $(0.014)$ & & \\
\hline PhD Students \% Minority & & & 0.001 & $(0.015)$ & & & -0.005 & $(0.015)$ \\
\hline (PhD\%Minority) x (Minority Student) & & & -0.002 & $(0.019)$ & & & 0.002 & $(0.019)$ \\
\hline \multicolumn{9}{|l|}{ University Characteristics } \\
\hline Undergraduates \% Black & & & & & $-0.019^{\wedge}$ & $(0.011)$ & & \\
\hline (Und\%Black) x (Black Student) & & & & & 0.003 & $(0.015)$ & & \\
\hline Undergraduates \% Hispanic & & & & & 0.006 & $(0.007)$ & & \\
\hline (Und\%Hispanic) x (Hispanic Student) & & & & & $-0.027^{*}$ & $(0.012)$ & & \\
\hline Undergraduates \% Asian & & & & & $-0.017^{*}$ & $(0.007)$ & & \\
\hline (Und\%Asian) x (Asian Student) & & & & & 0.018 & $(0.012)$ & & \\
\hline Undergraduate \% Minority & & & & & & & -0.020 & $(0.013)$ \\
\hline (Und\%Minority) x (Minority Student) & & & & & & & 0.005 & $(0.013)$ \\
\hline Undergraduates \% Female & & & & & 0.002 & $(0.009)$ & 0.004 & $(0.008)$ \\
\hline (Und\%Female) x (Female Student) & & & & & -0.006 & $(0.014)$ & -0.007 & $(0.014)$ \\
\hline Univ Faculty \% Female & & & & & $-0.019 *$ & $(0.009)$ & $-0.022 *$ & $(0.009)$ \\
\hline (UFac\%Female) x (Female Student) & & & & & 0.019 & $(0.015)$ & 0.020 & $(0.015)$ \\
\hline \multicolumn{9}{|l|}{ Faculty-Student Demographic Match } \\
\hline Professor and Student Black & -0.004 & $(0.071)$ & -0.013 & $(0.072)$ & 0.008 & $(0.070)$ & -0.004 & $(0.071)$ \\
\hline Professor and Student Hispanic & 0.020 & $(0.075)$ & 0.019 & $(0.075)$ & 0.020 & $(0.079)$ & 0.003 & $(0.080)$ \\
\hline Profess or and Student Indian & $0.065^{\wedge}$ & $(0.038)$ & 0.061 & $(0.039)$ & $0.079^{\wedge}$ & $(0.042)$ & $0.075^{\wedge}$ & $(0.043)$ \\
\hline Professor and Student Chinese & $0.148 * *$ & $(0.051)$ & $0.143^{* *}$ & $(0.050)$ & $0.146^{* *}$ & $(0.053)$ & $0.143^{* *}$ & $(0.054)$ \\
\hline Professor and Student Female & -0.003 & $(0.013)$ & -0.003 & $(0.012)$ & -0.001 & $(0.013)$ & 0.000 & $(0.012)$ \\
\hline Observations & & $206^{\mathrm{a}}$ & & $206^{\mathrm{a}}$ & & $852^{b}$ & & $852^{b}$ \\
\hline
\end{tabular}

Controls: Recipient: Race, Gender, Position (Full, Assoc., Asst.); Request for Now; Request for Now Interacted with Each Student Race-Gender Combination (Cauc. Male Omitted); School Rank; Student: Race, Gender, Race-Gender Interactions Note. All continuous variables included as moderators were standardized before creating interaction terms. ${ }^{\wedge}$ Significant at the $10 \%$ level. *Significant at 5\% level. **Significant at $1 \%$ level. ***Significant at the $0.1 \%$ level. ${ }^{\text {a }}$ For 20 of the 109 narrow disciplinary categories into which faculty were classified, the 2004 NSOFP survey reported no data. These observations corresponded to 313 data points from our study, which we excluded from our analyses. We also exclude data points for the 29 professors working in departments that could not be classified. ${ }^{b}$ For 12 of the universities studied, information is missing about the student body's composition. This missing data leads us to drop 354 data points in Models 3 and 4. 
Table 4. Estimated effects of students' race and gender, characteristics of faculty's academic discipline and university, and the interaction between minority student status and these discipline and university characteristics on whether faculty respond to emails. Standard errors are clustered by university and academic discipline. The Appendix offers definitions for the primary predictor variables in this table.

\begin{tabular}{|c|c|c|c|c|c|c|c|c|}
\hline & \multicolumn{2}{|c|}{ Model 5} & \multicolumn{2}{|c|}{ Model 6} & \multicolumn{2}{|c|}{ Model 7} & \multicolumn{2}{|c|}{ Model 8} \\
\hline & $\beta$ & Std. Err. & $\beta$ & Std. Err. & $\beta$ & Std. Err. & $\beta$ & Std. Err. \\
\hline \multicolumn{9}{|l|}{ Academic Discipline Characteristics } \\
\hline Avg. Faculty Pay & 0.000 & $(0.016)$ & 0.004 & $(0.016)$ & 0.004 & $(0.016)$ & 0.006 & $(0.016)$ \\
\hline (Pay) x (Minority or Female Student) & $-0.044 *$ & $(0.018)$ & $-0.048 * *$ & $(0.018)$ & $-0.048 * *$ & $(0.018)$ & $-0.050 * *$ & $(0.018)$ \\
\hline \multicolumn{9}{|l|}{ University Characteristics } \\
\hline Public School & & & $-0.101 * * *$ & $(0.026)$ & $-0.101 * *$ & $(0.033)$ & $-0.107 * * *$ & $(0.033)$ \\
\hline (Public) x (Minority or Female Student) & & & $0.140 * * *$ & $(0.029)$ & $0.140 * * *$ & $(0.035)$ & $0.146^{* * *}$ & $(0.035)$ \\
\hline School Rank (US News) & -0.006 & $(0.006)$ & $-0.010^{\wedge}$ & $(0.006)$ & -0.010 & $(0.020)$ & -0.008 & $(0.020)$ \\
\hline (School Rank) x (Minority or Female Student) & & & & & 0.000 & $(0.022)$ & -0.002 & $(0.022)$ \\
\hline \multicolumn{9}{|l|}{ Faculty Status } \\
\hline Profess orial Rank & & & & & & & 0.006 & $(0.018)$ \\
\hline (Prof Rank) x (Minority or Female Student) & & & & & & & -0.001 & $(0.019)$ \\
\hline \multicolumn{9}{|l|}{ Faculty-Student Demographic Match } \\
\hline Professor and Student Black & -0.009 & $(0.073)$ & -0.010 & $(0.074)$ & -0.010 & $(0.073)$ & -0.014 & $(0.075)$ \\
\hline Professor and Student Hispanic & 0.012 & $(0.074)$ & 0.007 & $(0.074)$ & 0.007 & $(0.074)$ & 0.001 & $(0.073)$ \\
\hline Professor and Student Indian & $0.066^{\wedge}$ & $(0.040)$ & $0.066^{\wedge}$ & $(0.039)$ & $0.066^{\wedge}$ & $(0.039)$ & 0.064 & $(0.039)$ \\
\hline Professor and Student Chinese & $0.146^{* *}$ & $(0.050)$ & $0.145^{* *}$ & $(0.049)$ & $0.145^{* *}$ & $(0.049)$ & $0.148^{* *}$ & $(0.048)$ \\
\hline Professor and Student Female & -0.006 & $(0.012)$ & -0.006 & $(0.012)$ & -0.006 & $(0.012)$ & -0.005 & $(0.012)$ \\
\hline Observations & \multicolumn{2}{|c|}{$6,206^{\mathrm{a}}$} & \multicolumn{2}{|c|}{$6,206^{\mathrm{a}}$} & \multicolumn{2}{|c|}{$6,206^{\mathrm{a}}$} & \multicolumn{2}{|c|}{$6,206^{\mathrm{a}}$} \\
\hline
\end{tabular}

Controls: Recipient: Race, Gender, Position (Full, Assoc., Asst.); Request for Now; Request for Now Interacted with Each Student RaceGender Combination (Cauc. Male Omitted); School Rank; Student: Race, Gender, Race-Gender Interactions

Note. The characteristics of academic disciplines and universities included as predictors in Table 3 are not included in these models for the sake of simplicity (and because these predictors were not jointly statistically significant). However, adding these predictors to Models 5-8 does not meaningfully change any results in terms of magnitude or statistical significance and these analyses are all available upon request. All continuous variables included as moderators were standardized before creating interaction terms. ^Significant at the $10 \%$ level. *Significant at $5 \%$ level. **Significant at $1 \%$ level. $* * *$ Significant at the $0.1 \%$ level. ${ }^{a}$ For 20 of the 109 narrow disciplinary categories into which faculty were classified, the 2004 NSOFP survey reported no data. These observations corresponded to 313 data points from our study, which we excluded from our analyses. We also exclude data points for the 29 professors working in departments that could not be classified. 


\section{APPENDIX}

\section{Human Subjects Protections}

The two lead authors of this paper conducted all data collection and data analysis for the project. Before the start of data collection, the project was carefully reviewed and approved by both of their institutional review boards. Each IRB determined that a waiver of informed consent was appropriate based on Federal regulations (45 CFR 46.116(d)), which state the following:

"An IRB may approve a consent procedure which does not include, or which alters, some or all of the elements of informed consent set forth in this section, or waive the requirements to obtain informed consent provided the IRB finds and documents that: (1) The research involves no more than minimal risk to the subjects; (2) The waiver or alteration will not adversely affect the rights and welfare of the subjects; (3) The research could not practicably be carried out without the waiver or alteration; and (4) Whenever appropriate, the subjects will be provided with additional pertinent information after participation."

This project met all of the stated regulatory requirements for a waiver of informed consent. Informed consent would have eliminated the realism of the study and biased the sample of participants towards those most willing to talk with students. Two weeks after the study's launch, each study participant received an email debriefing him/her on the research purpose of the message he/she had recently received from a prospective doctoral student. Every piece of information that could have been used to identify the faculty participants in our study was deleted from all study databases within two weeks of the study's conclusion.

\section{Experimental Stimuli: Prospective Student Names}

Generating appropriate names for the fictitious students contacting faculty was a critical component of our experimental design. We relied on previous research to help generate names signaling both the gender and race (Caucasian, Black, Hispanic, Indian, Chinese) of these fictional students (Bertrand and Mullainathan, 2004; Lauderdale and Kestenbaum, 2000). We also looked to U.S. Census data documenting the frequency with which common surnames 
belong to Caucasian, Black, and Hispanic citizens and examined websites recommending baby names targeted at different racial groups. These sources provided a guide for generating a list of 90 names for potential use in our study, nine of each race and gender of interest.

We pretested each of these 90 names by surveying 38 people, all of whom had a Masters Degree $(87.5 \%)$ or a $\mathrm{PhD}(12.5 \%)$ and who had signed up through Qualtrics to complete online polls for pay. We asked 18 of these survey respondents to complete a survey about the gender conveyed by each of the 90 names in our sample, and we asked 20 respondents to complete a survey about the race conveyed by each of the 90 names in our sample. Participants in the gender survey were asked to "Please make your best guess as to the identity of a person with the following name:" and were required to choose between "Male" and "Female" for each name. Participants in the race survey were also asked to "Please make your best guess as to the identity of a person with the following name:" and were required to choose between "Caucasian," "Black," "Hispanic," "Chinese," "Indian," and "Other" for each name. Both the gender and the race survey were 10 pages long with questions about a randomly ordered set of nine names presented on each survey page.

The responses generated by the above survey were tabulated, and we selected the two names for use in our study of each race and gender with the highest net race and gender recognition rates. Table 1 presents a list of the names used in our study along with their correct race and gender recognition rates in the survey pre-test described above. Respondents accurately identified the selected names at an average rate of $97 \%$ and $98 \%$ for race and gender respectively.

\section{Classifying Faculty Race and Gender}


Research assistants determined the gender of faculty participants by studying the faculty names, visiting their websites, examining photos, and reading research summaries containing gendered statements (e.g., "she studies"). An automated technique was initially used for racial classification followed by manual validation by research assistants. The automated technique relied on lists of: (a) the 639 highest-frequency Hispanic surnames as of 1996 (Word and Perkins, 1996), and (b) 1,200 Chinese and 2,690 Indian surnames (Lauderdale and Kestenbaum, 2000). These lists were compared to the surnames of each faculty member, and if a surname match was identified, a faculty member was classified as a member of the associated racial group. Next, these automated classifications were validated for Hispanic, Indian, and Chinese faculty by research assistants who again visited faculty websites. Further, research assistants generated racial classifications for faculty who were Caucasian, Black, or another race besides Hispanic, Indian, or Chinese. This process involved visiting faculty websites, examining faculty CVs, and relying on Google image searches to find pictures of faculty on the internet. In rare instances when research assistants determined it was not possible to reliably classify a faculty member's race, another professor whose race could be validated was chosen as a replacement representative of the doctoral program in question.

\section{Assignment of Sample Weights}

In those regressions and robustness checks that include sample weights and in all summary statistics reported (which are always sample-weighted), sample weights are determined for a given observation as a function of the race of the faculty member contacted, $r$, his or her academic discipline, $d$, and the race of the student who contacted the faculty member, $s$, as follows. First, the expected representative number of faculty in a given academic discipline, $d$, of a given race, $r$, is calculated (e.g., since professors in Ph.D. granting departments in 
Engineering and Computer Science are $77.8 \%$ Caucasian and the study included 1,125

Engineering and Computer Science faculty, the expected number of Caucasian Engineering and Computer Science faculty is $1,125 * 0.778=875) .{ }^{8}$ We refer to this quantity as $e_{r, d}$. Next, the expected number of faculty of a given race, $r$, in a given discipline, $d$, receiving emails from students of a given race, $s$, is calculated assuming balanced randomization. This is simply $e_{r, d} / 5$ since there are five student races represented in our study (e.g., the expected number of Caucasian faculty in computer science and engineering departments receiving emails from Caucasian students is $875 / 5=175$ ). We refer to this quantity as $e_{r, s, d}$. Finally, we calculate the actual number of faculty in a given discipline, $d$, of a given race, $r$, receiving emails from students of a given race, $s$ (e.g., 151 Caucasian faculty in engineering and computer science departments actually received emails from Caucasian students). We refer to this quantity as $a_{r, s, d}$. Sample weights are then constructed by taking the ratio: $e_{r, s, d} / a_{r, s, d}$. Thus, the sample weight for Caucasian faculty of engineering and computer science is $175 / 151=1.1592$.

\section{Raw Summary Statistics}

The fitted results presented in Figures 1 and 3 are nearly identical to the figures produced by simply examining raw, sample-weighted average summary statistics (available upon request).

\section{Robustness Checks}

Bias as a Function of Broad Academic Discipline. If we rely on logistic regressions rather than OLS regressions, we find remarkably similar patterns of discrimination across broad disciplines in the Academy. Six of the ten discipline-by-discipline estimates of the "discriminatory gap" in the treatment of minorities and females relative to Caucasian males are statistically significant (p's $<0.05$ ) and a seventh is marginally significant (social sciences; $\mathrm{p}<$

\footnotetext{
${ }^{8}$ Note that the "true" percentage of professors in a given discipline of a given race is estimated by examining the representative sample of faculty selected for study participation.
} 
0.10). Further, logistic regression analyses replicate the finding that bias plays a greater role in impeding females and minorities in certain disciplines than in others, consistent with Hypothesis 1. Specifically, a Wald Test of the hypothesis that the discriminatory gaps estimated across disciplines are jointly equal to one another indicates that our coefficient estimates of the size of the discriminatory gap by broad discipline differ significantly more from one another than would be expected by chance $\left(\chi^{2}=209.07 ; p<0.001\right)$, consistent with Hypothesis 1 . Again, bias against women and minorities is significantly higher in disciplines such as business and education than in the social sciences, humanities and natural sciences (for all six paired comparisons, p's < $0.05)$.

Moderators of Bias. The results presented in Tables 3-4 are meaningfully unchanged in terms of magnitude or statistical significance if the analysis is repeated using: (a) an ordinary least squares regression with sample weights and standard errors clustered by university or (b) an ordinary least squares regression with sample weights and standard errors clustered by narrow academic discipline. Further, the results presented in Tables 3-4 are nearly identical if the analysis is repeated using logistic regression models instead of ordinary least squares regressions models. All robustness checks are available upon request.

Alternative Outcome Variables. Finally, we observe a pattern of qualitatively similar results to those presented here if we turn our attention to alternative outcome variables such as response speed and whether an email generated an immediate offer from a faculty member to meet on the date of a student's campus visit, though the statistical significance of a number of the results presented here changes when these alternative outcome variables are instead examined. 
Table A1. Description of primary predictor variables included in regression analyses (see Tables 3-4).

\begin{tabular}{|c|c|}
\hline Name & Description \\
\hline [Category] Student & $\begin{array}{l}\text { Indicator variable that takes on a value of one when the } \\
\text { prospective PhD student who sent a meeting request is a } \\
\text { member of [Category]. For example, Hispanic Student takes on } \\
\text { a value of one when the student is Hispanic and zero otherwise. }\end{array}$ \\
\hline \multicolumn{2}{|l|}{ Academic Discipline Characteristics } \\
\hline $\begin{array}{l}\text { Faculty \% [Category] (also } \\
\text { Fac\%[Category]) }\end{array}$ & $\begin{array}{l}\text { The (standardized) percentage of faculty in the contacted } \\
\text { professor's academic discipline who are members of [Category]. } \\
\text { For example, Faculty \% Black would be the (standardized) } \\
\text { percentage of faculty in the contacted professor's discipline who } \\
\text { are Black. }\end{array}$ \\
\hline $\begin{array}{l}\text { PhD Students \% [Category] (also } \\
\text { PhD\%[Category]) }\end{array}$ & $\begin{array}{l}\text { The (standardized) percentage of PhD students in the contacted } \\
\text { professor's academic discipline who are members of [Category]. } \\
\text { For example, PhD Students \% Minority would be the } \\
\text { (standardized) percentage of PhD students in the contacted } \\
\text { professor's discipline who are members of the minority groups } \\
\text { we study here (Black, Hispanic, or Asian). }\end{array}$ \\
\hline Avg. Faculty Pay (also Pay) & $\begin{array}{l}\text { The (standardized) average 9-month salary in the contacted } \\
\text { professor's academic discipline according to the } 2004 \text { NSOFP. }\end{array}$ \\
\hline \multicolumn{2}{|l|}{ University Characteristics } \\
\hline $\begin{array}{l}\text { Undergraduate \% [Category] (also } \\
\text { Und\%[Category]) }\end{array}$ & $\begin{array}{l}\text { The (standardized) percentage of undergraduates at the } \\
\text { contacted professor's university who are members of } \\
\text { [Category]. For example, Undergraduates \% Asian would be } \\
\text { the (standardized) percentage of undergraduates at the contacted } \\
\text { professor's university who are Asian. }\end{array}$ \\
\hline $\begin{array}{l}\text { Univ Faculty \% [Category] (also } \\
\text { UFac\%[Category]) }\end{array}$ & $\begin{array}{l}\text { The (standardized) percentage of faculty at the contacted } \\
\text { professor's university who are members of [Category]. For } \\
\text { example, Univ Faculty \% Female would be the (standardized) } \\
\text { percentage of faculty at the contacted professor's university who } \\
\text { are Female. }\end{array}$ \\
\hline Public School (also Public) & $\begin{array}{l}\text { Indicator variable that takes on a value of one when the } \\
\text { contacted professor works for a public university and zero } \\
\text { otherwise. }\end{array}$ \\
\hline $\begin{array}{l}\text { School Rank (US News) (also } \\
\text { School Rank) }\end{array}$ & $\begin{array}{l}\text { The (standardized) US News and World Report } 2010 \text { ranking (1- } \\
\text { 260) of the contacted professor's university. }\end{array}$ \\
\hline \multicolumn{2}{|l|}{ Faculty-Student Demographic Match } \\
\hline Professor and Student [Category] & $\begin{array}{l}\text { Indicator variable that takes on a value of one when the } \\
\text { contacted professor and the prospective PhD student who sent } \\
\text { the meeting request are both members of the same [Category]. } \\
\text { For example, Professor and Student Hispanic takes on a value } \\
\text { of one when both the professor and student are Hispanic and } \\
\text { zero otherwise. }\end{array}$ \\
\hline \multicolumn{2}{|l|}{ Faculty Status } \\
\hline Professorial Rank (also Prof Rank) & $\begin{array}{l}\text { Variable capturing the contacted professor's level of academic } \\
\text { rank, which takes on a value of } 1 \text { for assistant professors, } 2 \text { for } \\
\text { associate professors, and } 3 \text { for full professors. }\end{array}$ \\
\hline
\end{tabular}


Table A2. NSOFP Narrow Disciplinary Categories.

\begin{tabular}{|c|c|c|c|c|c|c|c|c|c|}
\hline \multicolumn{10}{|c|}{ Narrow Sub-Disciplines within Each Broad Discipline Studied } \\
\hline Business & Education & $\begin{array}{c}\text { Engineering } \\
\text { and Computer } \\
\text { Science }\end{array}$ & Fine Arts & $\begin{array}{c}\text { Health } \\
\text { Sciences }\end{array}$ & $\begin{array}{l}\text { Human } \\
\text { Services }\end{array}$ & Humanities & Life Sciences & $\begin{array}{c}\text { Natural, } \\
\text { Physical } \\
\text { Sciences } \\
\text { and Math }\end{array}$ & Social Sciences \\
\hline $\begin{array}{l}\text { (1)Accounting and } \\
\text { related services } \\
\text { (2)Business } \\
\text { admin/management } \\
\text { / operations } \\
\text { (3)Finance/financia } \\
1 \text { management } \\
\text { services } \\
\text { (4)Human } \\
\text { resources } \\
\text { management and } \\
\text { services } \\
\text { (5)Marketing } \\
\text { (6)Business/mgt/ } \\
\text { marketing/related, } \\
\text { other } \\
\text { (7)Management } \\
\text { information } \\
\text { systems/services }\end{array}$ & $\begin{array}{l}\text { (1)Curriculum and } \\
\text { instruction } \\
\text { (2)Educational } \\
\text { administration/ } \\
\text { supervision } \\
\text { (3)Educational/ } \\
\text { instructional media } \\
\text { design } \\
\text { (4)Elementary } \\
\text { education and } \\
\text { teaching } \\
\text { (5)Student } \\
\text { counseling/ } \\
\text { personnel services } \\
\text { (6)Education, other } \\
\text { (7)Early childhood } \\
\text { education and } \\
\text { teaching } \\
\text { (8)Special education } \\
\text { and teaching } \\
\text { (9)Secondary } \\
\text { education and } \\
\text { teaching } \\
\text { (10)Adult and } \\
\text { continuing } \\
\text { education/teaching } \\
\text { (11)Teacher ed: } \\
\text { specific levels, other } \\
\text { (12)Teacher ed: } \\
\text { specific subject areas } \\
\text { (13)Bilingual \& } \\
\text { multicultural } \\
\text { education } \\
\text { (14)Ed assessment } \\
\text { (15)Higher education } \\
\text { (16)Library science }\end{array}$ & $\begin{array}{l}\text { (1)Architecture and } \\
\text { related services } \\
\text { (2)Computer science } \\
\text { (3)Computer } \\
\text { software and media } \\
\text { applications } \\
\text { (4)Information } \\
\text { science/studies } \\
\text { (5)Computer/info sci/ } \\
\text { support svcs, other } \\
\text { (6)Biomedical/medic } \\
\text { al engineering } \\
\text { (7)Chemical } \\
\text { engineering } \\
\text { (8)Civil engineering } \\
\text { (9)Computer } \\
\text { engineering } \\
\text { (10)Electrical \& } \\
\text { communications } \\
\text { engineering } \\
\text { (11)Engineering } \\
\text { technologies/ } \\
\text { technicians } \\
\text { (12)Environmental/ } \\
\text { environmental health } \\
\text { eng } \\
\text { (13)Mechanical } \\
\text { engineering } \\
\text { (14)Engineering, } \\
\text { other }\end{array}$ & $\begin{array}{l}\text { (1)Art } \\
\text { history, } \\
\text { criticism \& } \\
\text { conservation } \\
\text { (2)Design \& } \\
\text { applied arts } \\
\text { (3)Drama/the } \\
\text { atre arts and } \\
\text { stagecraft } \\
\text { (4)Fine and } \\
\text { studio art } \\
\text { (5)Music, } \\
\text { general } \\
\text { (6)Music } \\
\text { history, } \\
\text { literature, } \\
\text { and theory } \\
\text { (7)Visual and } \\
\text { performing } \\
\text { arts, other } \\
\text { (8)Dance }\end{array}$ & $\begin{array}{l}\text { (1)Clinical/medical } \\
\text { lab science/allied } \\
\text { (2)Dentistry } \\
\text { (3)Health \& medical } \\
\text { administrative } \\
\text { services } \\
\text { (4)Allied health and } \\
\text { medical assisting } \\
\text { serv } \\
\text { (5)Allied health } \\
\text { diagnostic/intervent/ } \\
\text { treat } \\
\text { (6)Medicine, } \\
\text { including psychiatry } \\
\text { (7)Mental/social } \\
\text { health services and } \\
\text { allied } \\
\text { (8)Nursing } \\
\text { (9)Pharmacy/pharm } \\
\text { aceutical } \\
\text { sciences/admin } \\
\text { (10)Public health } \\
\text { (11)Rehabilitation } \\
\& \text { therapeutic } \\
\text { professions } \\
\text { (12)Veterinary } \\
\text { medicine }\end{array}$ & $\begin{array}{l}\text { (1)Legal } \\
\text { professions and } \\
\text { studies, other } \\
\text { (2)Family/consu } \\
\text { mer sciences, } \\
\text { human sciences } \\
\text { (3)Parks, } \\
\text { recreation and } \\
\text { leisure studies } \\
\text { (4)Health and } \\
\text { physical } \\
\text { education/fitness } \\
\text { (5)Theology and } \\
\text { religious } \\
\text { vocations } \\
\text { (6)Public } \\
\text { administration } \\
\text { (7)Social work } \\
\text { (8)Public } \\
\text { administration \& } \\
\text { social svcs oth } \\
\text { (9)Criminal } \\
\text { justice } \\
\text { (10)Fire } \\
\text { protection }\end{array}$ & $\begin{array}{l}\text { (1)English } \\
\text { language and } \\
\text { literature/letters } \\
\text { (2)Foreign } \\
\text { languages/literat } \\
\text { ure/ linguistics } \\
\text { (3)Philosophy } \\
\text { (4)Religion/relig } \\
\text { ious studies } \\
\text { (5)History }\end{array}$ & $\begin{array}{l}\text { (1)Agriculture and } \\
\text { related sciences } \\
\text { (2)Natural } \\
\text { resources and } \\
\text { conservation } \\
\text { (3)Biochem/ } \\
\text { biophysics/ } \\
\text { molecular biology } \\
\text { (4)Botany/plant } \\
\text { biology } \\
\text { (5)Microbiological } \\
\text { sciences \& } \\
\text { immunology } \\
\text { (6)Genetics } \\
\text { (7)Physiology, } \\
\text { pathology \& related } \\
\text { sciences } \\
\text { (8)Zoology/animal } \\
\text { biology } \\
\text { (9)Biological \& } \\
\text { biomedical } \\
\text { sciences, other }\end{array}$ & $\begin{array}{l}\text { (1)Mathematics } \\
\text { (2)Statistics } \\
\text { (3)Astronomy \& } \\
\text { astrophysics } \\
\text { (4)Atmospheric } \\
\text { sciences and } \\
\text { meteorology } \\
\text { (5)Chemistry } \\
\text { (6)Geological \& } \\
\text { earth sciences/ } \\
\text { geosciences } \\
\text { (7)Physics } \\
\text { (8)Physical } \\
\text { sciences, other } \\
\text { (9)Science } \\
\text { technologies/ } \\
\text { technicians }\end{array}$ & $\begin{array}{l}\text { (1)Area/ethnic/cultural/ } \\
\text { gender studies } \\
\text { (2)Communication// } \\
\text { journalism/related pgms } \\
\text { (3)Communication } \\
\text { technologies } \\
\text { (4)Law } \\
\text { (5)Multi/interdisciplinar } \\
\text { y studies } \\
\text { (6)Behavioral } \\
\text { psychology } \\
\text { (7)Clinical psychology } \\
\text { (8)Education/school } \\
\text { psychology } \\
\text { (9)Psychology, other } \\
\text { (10)Anthropology } \\
\text { (except psychology) } \\
\text { (11)Archeology } \\
\text { (12)International } \\
\text { relations \& affairs } \\
\text { (13)Political science and } \\
\text { government } \\
\text { (14)Geography \& } \\
\text { cartography } \\
\text { (15)Criminology } \\
\text { (16)Economics } \\
\text { (17)Sociology } \\
\text { (18)Urban studies/affairs } \\
\text { (19)Social sciences, } \\
\text { other }\end{array}$ \\
\hline
\end{tabular}

Note. Our detailed analyses of bias across disciplines (presented in Tables 5-6) examine bias at the level of a professor's narrow academic discipline as defined by the NSOFP (2004). The mapping of the 89 narrow NSOFP disciplines into the 10 broad NSOFP disciplines summarized in Figure 1 and Table 2 is shown

here. 